\title{
MJN TRAINING PROGRAM FOR IMPROVING CLINICAL TEACHING SKILLS AS A COMPETENCE OF CLINICAL INSTRUCTORS
}

\author{
Sally Shaapan Mallek*, Wafaa Abd El-Azeem El-Hosany \\ Nursing Administration, Faculty of Nursing, Suez Canal University, Egypt \\ *Corresponding Author’s Email: sally.shabban@nursing.suez.edu.eg
}

\begin{abstract}
Background: Clinical teaching is an important component of clinical education. In nursing, clinical teaching is ensured by clinical nurse educators. The quality of the student-teacher interaction in the clinical field can either facilitate or hinder the students' integration of theory to practice. The study aimed to assess the effect of training program on clinical teaching skills of the clinical instructors at faculty of nursing, Suez Canal University. Design: A quasi-experimental study design. Setting: this study was conducted in three settings as follows: Faculty of nursing SCU, Suez Canal university hospitals and Ismailia general hospital. Sample: Convenient sample were included all clinical instructors (43) who participate in students' clinical teaching during the academic years 2016/2017 and 2017/2018.Tools: Tool (1): Self-Need Assessment Sheet which included two parts. Part I: personnel data of clinical instructors, Part II: it contains question about the needs related to clinical teaching skills. Tool (2): clinical teaching skills observational checklist. Results: There was a statistically significant improvement between mean scores of clinical instructors in relation to their skills at pre, post and follow up. Mean score at pre-program was (46.6 \pm 4.62$)$ which increased at post program (82.4 \pm 2.8$)$ and slightly declined at follow-up to (82.1 \pm 2.93$)$. Conclusion: the clinical teaching skills of clinical instructors improved post and follow up implementation of the program compared to pre implementation of the program. Recommendations: Ongoing professional education for clinical instructors about clinical teaching skills and a clinical teaching efficacy scale must be developed to evaluate clinical nursing instructors based on the attributes of rules and their capabilities.
\end{abstract}

Keywords: Training Program, Clinical Teaching Skills, Clinical Instructors

\section{INTRODUCTION}

Clinical teaching is an important part and the lifeblood of nursing education (Heidari, 2015). It is an important component of the educational process than classroom learning (Oermann \& Gaberson, 2013). The educational process is unique in the practice professions because being able to perform the activities of the profession in real life situations as opposed to simply being able to express understanding of principles is a requisite competency of graduation (Kube, 2010).

The clinical teaching acts as a method to meet individual learner needs, it creates best learning environment that facilitates learner to socialize as nurse, it promotes development of the learner in improving knowledge, psychomotor skills and positive attitude, it raises challenges for student to face the nursing situation and it provide opportunities for real-life experiences and transfer of knowledge to practical situation (Baraz et al., 2015).

Training program is an organized procedure for increasing the knowledge and skills for clinical instructors for a definite purpose. Furthermore, training can be defined as an organized method of ensuring that clinical instructors have knowledge, skills for specific purpose, that they acquired the necessary knowledge and competencies to perform the duties of the job (Basavanthappa, 2012). Training is the acquisition of knowledge, skills, and competencies as a result of the teaching of vocational or practical skills and knowledge that relate to specific useful competencies, which has specific goals of improving one's capability, capacity, productivity and performance (Sudh, 2013). 
Clinical competence is the main factor for effective clinical learning. The competence of clinical instructors is regarded as the most significant factor in achieving training goals. This competence is a multi-dimensional concept. Overall, a qualified clinical trainer should have a comprehensive perspective. In other words, he/she should have five major characteristics: the ability to establish communication, educational qualifications, clinical competence, scholarly knowledge and academic status (Khan, 2015).

The clinical nursing instructor is responsible for managing, educating and supporting the student nursing during clinical practice that is most effective for facilitating learning process. Clinical instructor behavior and skills that enhance effective clinical instruction include: clinical teaching skills, having experience, having good communication skills, providing constructive feedback, facilitating a student-cantered environment and give student chance for training during clinical practice (Madhavanprabhakaran et al.,2013).

Clinical instructor's personality and manner of dealing with nursing students have potential upon student performance. The authoritarian, caustic, or impatient instructors may seriously inhibit or otherwise adversely affect the quality of student contribution in her or his class, cause student to avoid needed interviews, or build lasting negative attitude towards the course, the permissive, relatively undemanding, understanding instructors may encourage high level performance and good attitude learning (Brink \& Louw, 2012; Bulechek, 2013).

\section{Significance}

After observing the performance of clinical instructors at faculty of nursing-Suez Canal University, we discovered that clinical teaching skills need improvement, because the skills of clinical instructors in clinical setting plays an important role on the performance of nursing students. In order to get a better preparation of the students for clinical experience, the clinical instructors should be well-prepared for their roles in clinical setting especially the newly employed members. For these reasons this study will be done.

Moreover, Molodysky et al., (2006) and Mahfouz (2007) in their studies recommended that, training programs should be conducted for the faculty assistants to improve their abilities and skills for clinical teaching. Aziz (2005) in his study done at the faculty of nursing,
Ain Shams University recommended that the educational program is needed periodically on how demonstrators and assistant lecturers are practicing in clinical. Barden (2014) also recommended that an orientation program for newly appointed clinical instructors about clinical teaching skills is highly needed, for these reasons; this study was carried out to conduct a program in clinical teaching skills for clinical instructors.

\section{METHODOLOGY}

This study aimed to assess the effect of training program on clinical teaching skills of the clinical instructors at faculty of nursing, Suez Canal University through:

1. Assessing needs of clinical instructors related to clinical teaching skills.

2. Designing training program based on their need assessment.

\section{Implementing the training program.}

4. Evaluating the effect of the program on the clinical practice of clinical instructors.

\section{Research Hypotheses}

An educational program will cause an improvement in skills of clinical instructors through:

Increasing total scores of skills after conducting an educational program than before it.

\section{Subject and Methods}

\section{Research Design}

A quasi-experimental study design was used to conduct the present study.

\section{Research Setting}

The present study was conducted in three settings as follows:

- Faculty of Nursing, Suez Canal University where the program was implemented to the clinical instructors which include five scientific departments, which are: Medical Surgical Nursing, Nursing Administration, Pediatric Nursing, Maternity and Newborn Health Nursing and Psychiatric and Mental Health Nursing. Except Family and Community Health Nursing department, because they don't work with students in clinical setting, their work involves field work 
and community visits.

- Suez Canal University Hospitals which included different clinical unit where the nursing student are trained.

- Ismailia General Hospital which included different clinical unit where the nursing students are trained.

\section{Subjects}

Convenient sample included all clinical instructors who participate in student's clinical teaching during the academic years 2016/2017 and 2017/2018 at the following specialties: Nursing Administration, Medical Surgical Nursing, Maternity and Newborn Health Nursing, pediatric Nursing, and Psychiatric and Mental Health Nursing.

The total number of clinical instructors Was 43, 17 of them were demonstrators and 26 were assistant Lecturers at the Faculty of Nursing, Suez Canal University distributed as:

Table 1:Distribution of Clinical Instructors Regarding their Academic

\begin{tabular}{|l|c|c|}
\hline Variable & \multirow{2}{*}{ No } & \multirow{2}{*}{$\%$} \\
\cline { 1 - 2 } Academic department & 11 & 25.6 \\
\hline Medical Surgical Nursing & 7 & 16.3 \\
\hline Nursing Administration & 8 & 18.6 \\
\hline Pediatric Nursing & 9 & 20.9 \\
\hline Maternity and Newborn Health Nursing & 8 & 18.6 \\
\hline Psychiatric and Mental Health Nursing & 43 & 100 \\
\hline Total &
\end{tabular}

\section{Tools for Data Collection}

\section{First tool: Self-Need assessment sheet}

It was developed and constructed by Badran, (2014) through review of relevant literature (Billing \& Halstead, 2005; Gaberson \& Oermann, 2010). The need assessment sheet was used to assess clinical instructors' educational needs related to clinical teaching competencies. This contains two parts they are:

Part I: Personnel data of clinical instructors: it includes name, age, sex, years of experience, academic position, qualification before enrolment in faculty and department specialty.

Part II: It contains question about the needs related to clinical teaching skills it contains the following items: concept of adult learning, concept of clinical teaching, clinical learning cycle, and effective learning environment, writing educational objectives, clinical teaching strategies, effective presentation skills, seminar conduction and leading seminars, problem based learning, role of clinical trainer, effective communication, clinical supervision and evaluation, critical thinking, team building, time management, and documentation.

Scoring system: All items of need assessment which scored $80 \%$ or more were included in the study.

\section{Second Tool: Clinical Teaching Skills} Observational Checklist

It was developed by Badran, (2014) through review of related literature (Vanguri \& Konin, 2008; Mahfouz, 2011; Abd Rabou, 2011). The observational checklist contained ten dimensions involving 89 items as presented:

\section{Table 2: Observational Checklist}

\begin{tabular}{|l|c|}
\hline \multicolumn{1}{|c|}{ Dimensions } & Items \\
\hline Personal at tributes & 17 \\
\hline Demons tration skills & 9 \\
\hline Facil itation skills & 6 \\
\hline Assessment and coordination skills & 9 \\
\hline Supportive skills & 6 \\
\hline Trainer skills & 6 \\
\hline Interpersonal relation and communication skills & 10 \\
\hline Creating favorable learning environment skills & 11 \\
\hline Evaluator skil ls & 10 \\
\hline Critical thi nking sk ills & 5 \\
\hline \multicolumn{1}{|c|}{ Total } & $\mathbf{8 9}$ \\
\hline
\end{tabular}

\section{Administrative Phase}

To carry the study in the selected setting, an official permission for collection of data was obtained using proper channel of communication to conduct the study from the dean of faculty of nursing at Suez Canal University, with acceptance of directors of Suez Canal university hospitals and acceptance of directors of Ismailia general hospitals.

\section{Pilot Study}

A pilot study was carried out to test the questionnaire feasibility, understandability and to estimate the time consumed for filling in the forms. It was conducted on $10 \%$ of clinical instructors (4) who were selected randomly; the pilot study was excluded from the total sample. It was carried before data collection, to evaluate the content and clarity of questionnaire, reconstruct the questionnaire, if necessary, and estimate the time needs to fill questionnaire a brief explanation of the purpose of the study was provided to every participant in the pilot, 
and then they were provided with a copy of the study tools. The necessary modifications in form of changing few words were done according to comment made by clinical instructors.

\section{The Validity of the Tools}

Tools of data collection were tested for content validity by a panel of five experts from different specialties as Nursing Administration, Pediatric Nursing and Medical and Surgical Nursing from Faculties of Nursing at Cairo University and Suez Canal University. Modifications were done according to the experts' opinions.

\section{Tools Reliability}

The reliability of the tools was done by using (test and retest) measurement and applied time to be sure the consistency of answers. The reliability was assured utilizing Cronbach's alpha; it indicated that the tool has a reliability of 0.95 .

\section{Ethical Considerations}

Informed consent was obtained from a participant after explaining the purposes of the study, no harmful methodology used with the participant; they had the right to withdrawal from the study at any time.

\section{Fieldwork}

Data collection of the study was started at the beginning of October 2017, and was completed by the end of October 2018. The study was conducted through the following phases:

\section{Phase (1): Pre-planning Phase:}

This phase was concerned with an official permission obtained from the Dean of the Faculty of Nursing at Suez Canal University to conduct the study and to collect the data after the researcher explained the aim of the study.

Before program planning the researcher developed and distributed educational needs assessment sheet to the study subjects at their work department to assess their training needs about clinical teaching skills after explaining the aim of the study. The researcher observed performance of faculty assistants of clinical teaching skills by using observational checklist at clinical units, where the nurse students are trained. The observation was done three times during the study: the first observation was in October 2017 in the first semester of academic year 2017/2018 (before program implementation).

\section{Phase (2): Program Planning}

Program was constructed by the researcher after review of the related literature and based on the needs of the clinical instructors, according to the result of the observation of performance, designing program about clinical teaching skills for clinical instructors. This program aims at improving clinical teaching skills of clinical instructors' members. The time allowed for achieving the program was $32 \mathrm{hr}$.: 16 theoretical and 16 practical for all clinical instructors at after mentioned departments, the program sessions started from 10 am to $12 \mathrm{pm}$; two hours in every session, one day per week for three months.

The components of the program include sessions about concept of clinical teaching, concept of adult learning, clinical learning cycle, effective clinical learning environment, role of clinical trainer, how to write educational objectives, teaching strategies, effective presentation skills, how to conduct and lead seminars, problem based learning, effective communication, clinical supervision and evaluation, problem solving and critical thinking, team building, time management and documentation.

\section{Phase (3): Program Implementation}

The program was implemented at the Faculty of Nursing, Suez Canal University to the clinical instructors who are working at the predetermined departments. The program was implemented throughout three months (January, February \& March 2018); one day per week, one session was offered daily, two hours for each session. In (January \& February) 2018 the program provided for three departments, Nursing Administration department, Pediatric nursing $\&$ Physiatrist and mental Health Nursing department. At the end of the February 2018, in the last session, a post test was done to assess knowledge of faculty assistants after the program. As well, in March 2018, the program also provided for Medical \& Surgical Nursing department, and Maternity and Newborn Health Nursing. One day per week, one session was offered daily, two hours for each session. At the end of March in the last session, a post test was done to assess knowledge of clinical instructors after the program. The program took about three months (Janaury, February \& March, 2018).

Each session lasted for 2 hours ( $1 \mathrm{hr}$ theory and $1 \mathrm{hr}$. practice). In the first session the researcher explained the aim of the study, program objectives, plan and 
content. In the first session a pretest was done to assess knowledge about clinical teaching skills before the program. At the beginning of each session, the objective of the session was explained. Daily feedback was done about the previous session and at the end of each session.

The teaching method used during the implantation of the program were lecture, discussion, role play, group activities, and practice session such as setting objectives individually, small group activities to apply critical thinking and problem solving and role play to apply communication skills, apply different methods of teaching, apply problem based learning session, and role play for effective presentation and team building and giving effective feedback, and group activity for applying time management tools, and role play for different types of records used in nursing units. Teaching aids used were data show, and flip chart. The researcher distributed a booklet about content of the program to all clinical instructors who share on the study.

\section{Phase (4): Follow up (Post - test)}

After implementing the program; post-test was done to evaluate clinical teaching knowledge of clinical instructors. The post-test was done immediately at the beginning of April 2018 by end of the educational program sessions implementation using the same tools which were used in the pretest, and because there is summer holiday, the follow-up test was postponed to October 2018.

\subsection{Statistical Analysis}

Data were fed to the computer and analyzed using IBM SPSS software package version 20.0. (Armonk, NY: IBM Corp)

The following statistical techniques were used:

- Percentage

- Mean score degree X.

- Standard deviation SD.

- Paired T test

- ANOVA test

- Proportion probability of error ( $p$-value) and confidence interval.

A significance level value was considered at $p<0.05$. Also, Cronbach's alpha was used to test the internal consistency of the performance evaluation tool.

\section{RESULTS}

Table 3: demonstrates the socio demographic characteristics of the studied clinical instructors (Cis). As regards age, more than half (58.2\%) of the CIs their age ranged from (26-30). Majority of CIs (81.4\%) were females. in relation to years of experience, more than two fifth $(44.2 \%)$ of them had $(3-<5)$ years of experiences in clinical teaching. as regard to specialty the lowest percentage $(16.3 \%)$ was related to nursing administration.

\section{Table 3: Socio-Demographic Characteristics}

\begin{tabular}{|c|c|c|}
\hline Variable & $\mathbf{N}$ & $\%$ \\
\hline \multicolumn{3}{|l|}{ Age } \\
\hline$<26$ & 17 & 39.5 \\
\hline $26-30$ & 25 & 58.2 \\
\hline$>30$ & 1 & 2.3 \\
\hline \multicolumn{3}{|l|}{ Sex } \\
\hline Female & 35 & 81.4 \\
\hline Male & 8 & 18.6 \\
\hline \multicolumn{3}{|l|}{ Years of experience } \\
\hline$<1$ & 5 & 11.6 \\
\hline $1:<3$ & 10 & 23.3 \\
\hline $3:<5$ & 19 & 44.2 \\
\hline $5:<=7$ & 9 & 20.9 \\
\hline \multicolumn{3}{|l|}{ Academic position } \\
\hline Demonstrator & 17 & 39.5 \\
\hline Assistant lecture $r$ & 26 & 60.5 \\
\hline \multicolumn{3}{|l|}{ Qualification before enrolment in faculty } \\
\hline Secondary education & 35 & 81.4 \\
\hline Nursing education & 8 & 18.6 \\
\hline \multicolumn{3}{|l|}{ Specialty } \\
\hline Medical Surgical Nursing & 11 & 25.6 \\
\hline Pediatric Nursing & 8 & 18.6 \\
\hline Obstetric and Gynecological Nursing & 9 & 20.9 \\
\hline Psychiatric and Mental Health Nursing & 8 & 18.6 \\
\hline Nursing Administration & 7 & 16.3 \\
\hline
\end{tabular}

Figure 1 shows that most CIs (76.7\%) did not attain any training program related to clinical teaching, while the minority (23.3\%) of them attained training program related to clinical teaching.

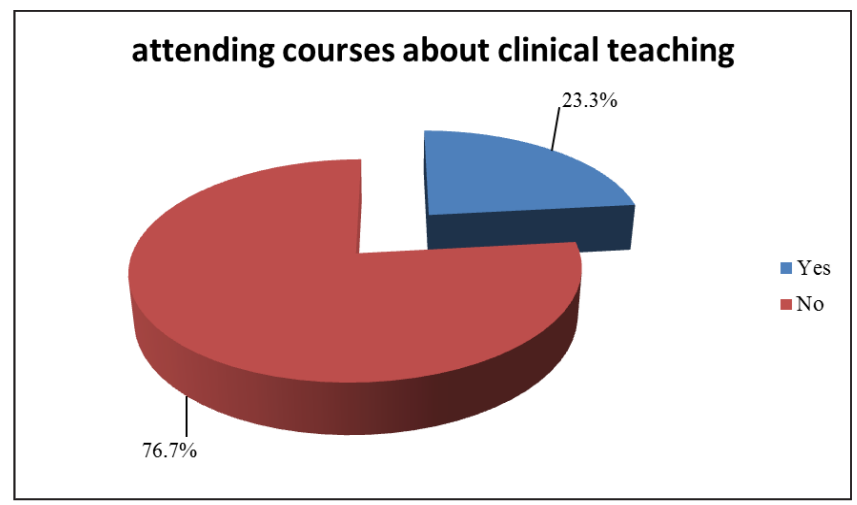

Figure 1: Clinical Teaching Course Attendance 
Table 4 clarifies that the needs of clinical instructors related to clinical teaching skills ranged from $81.3 \%$ to $95.3 \%$. Also, the table displayed that the highest percentage of needs was related to role of clinical trainer $(95.34 \%)$ and clinical teaching strategies $(93.02 \%)$ and the lowest percentage was related to concept of adult learning $(81.3 \%)$.

Table 4: Percentage Distribution of Training Needs as Reported by Clinical Instructors Regarding Clinical Teaching Skills

\begin{tabular}{|c|l|c|c|}
\hline \multicolumn{2}{|c|}{ Clinical teaching needs \# } & N & \% \\
\hline 1. & Concept of adult learning & 35 & 81.3 \\
\hline 2. & Concept of clinical teaching & 38 & 88.37 \\
\hline 3. & Clinical learning cycle & 39 & 90.69 \\
\hline 4. & Effective learning environment & 38 & 88.37 \\
\hline 5. & How to formulate educational objectives & 36 & 83.72 \\
\hline 6. & Clinical teaching strategies & 40 & 93.02 \\
\hline 7. & Effective presentation skills & 38 & 88.37 \\
\hline 8. & Seminar conduction \& leading seminars & 39 & 90.69 \\
\hline 9. & Problem based learning in clinical teaching & 38 & 88.37 \\
\hline 10. & Role of clinical trainer & 41 & 95.34 \\
\hline 11. & Effective communication & 38 & 88.37 \\
\hline 12. & Clinical supervision and evaluation & 39 & 90.69 \\
\hline 13. & Critical thinking & 40 & 93.02 \\
\hline 14. & Team building & 40 & 93.02 \\
\hline 15. & Time management & 39 & 90.69 \\
\hline 16. & Documentation & 40 & 93.02 \\
\hline
\end{tabular}

\#NB: total not equal 100\% because more than one of the study subjects chooses more than lecture.

Table 5 clarifies clinical instructors' adequate performance regarding appearance and voice characteristics throughout the program. It is noticed from the table, in pre-program phase all of CIs (100\%) had highest performance related to physically capable and mentally alert and the percentage remained the same in post and follow-up phase. At post program the most of them $(95.3 \%)$ had highest performance related to clear and easily heard voice. While at follow-up, the highest percentage of CIs $(90.7 \%)$ had highest performance related to speak at an appropriate pace.

Table 5: Clinical Instructors Adequate Performance Regarding Personal Attributes (Appearance \& Voice Characteristics) throughout the Program ( $N=43)$

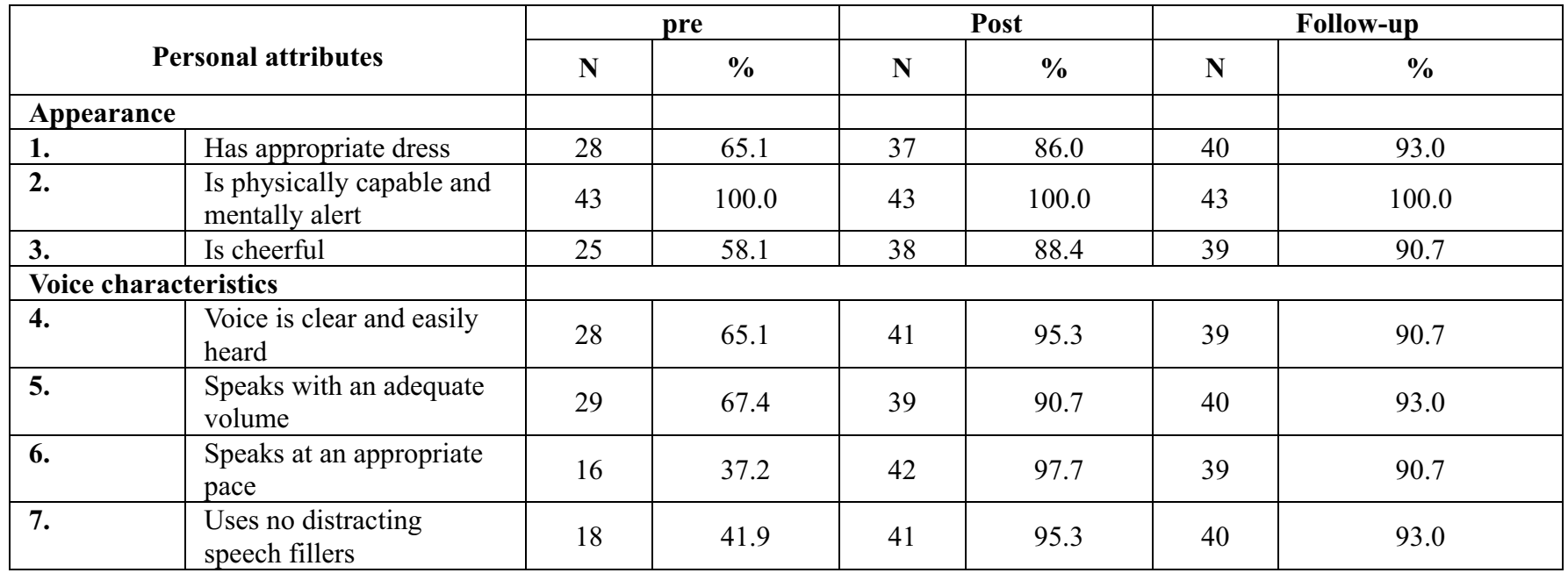


Table 6 shows clinical instructors' adequate performance regarding personal attributes (body languages \& personality) throughout the program. The majority $(72.1 \%$ \& $67.4 \%)$ of CIs had highest performance at pre-program phase related to face students while speaking and has good sense of humor.
However, most of them (95.3\%) had highest performance related to exhibits facial gestures or expressions, flexible and has patient in clinical area with students at post program. At follow-up, most (95.3\%) of CIs had highest performance related to be patient in clinical area with students.

Table 6: Clinical Instructors Adequate Performance Regarding Personal Attributes (Body Languages \& Personality) throughout the Program ( $N=43)$

\begin{tabular}{|c|c|c|c|c|c|c|c|}
\hline \multirow{2}{*}{\multicolumn{2}{|c|}{ Personal Attributes }} & \multicolumn{2}{|c|}{ Pre } & \multicolumn{2}{|c|}{ Post } & \multicolumn{2}{|c|}{ Follow-up } \\
\hline & & $\mathbf{N}$ & $\%$ & $\mathbf{N}$ & $\%$ & $\mathbf{N}$ & $\%$ \\
\hline \multicolumn{8}{|c|}{ Body languages } \\
\hline 1. & Faces students while speaking & 31 & 72.1 & 39 & 90.7 & 38 & 88.3 \\
\hline 2. & Establishes and maintains eye contact & 18 & 41.9 & 40 & 93.0 & 39 & 90.7 \\
\hline 3. & Exhibits facial gestures or expressions & 23 & 53.5 & 41 & 95.3 & 39 & 90.7 \\
\hline 4. & Moves occasionally while speaking & 23 & 53.5 & 40 & 93.0 & 37 & 86.0 \\
\hline 5. & Shows no distracting movements or gestures & 22 & 51.2 & 39 & 90.7 & 38 & 88.3 \\
\hline \multicolumn{8}{|c|}{ Personality } \\
\hline 1. & Is flexible & 24 & 55.8 & 41 & 95.3 & 40 & 93.0 \\
\hline 2. & Has good sense of humor & 29 & 67.4 & 40 & 93.0 & 40 & 93.0 \\
\hline 3. & Is open minded and non-judgmental & 19 & 44.2 & 40 & 93.0 & 40 & 93.0 \\
\hline 4. & Able to admit mistakes honestly & 16 & 37.2 & 39 & 90.7 & 37 & 86.0 \\
\hline 5. & Has patient in clinical area with students & 28 & 65.1 & 41 & 95.3 & 41 & 95.3 \\
\hline
\end{tabular}

Table 7 displays clinical instructors' adequate performance regarding demonstration skills throughout the program. According to the table, three fifth $(60.5 \%)$ of FAs had highest performance at pre-program related to Orients students about the objective of clinical Procedure, while the majority of them $(95.3 \%)$ had the highest performance related to orients students about the objective of clinical procedures and gives feedback to student about his performance at post program. However, at follow up the majority $(93.0 \%)$ of CIs had highest performance related to orients students about the objective of clinical procedure and observes students in clinical procedures.

Table 7: Clinical Instructors Adequate Performance Regarding Demonstration Skills throughout the Program (N=43)

\begin{tabular}{|c|c|c|c|c|c|c|c|}
\hline \multirow{2}{*}{\multicolumn{2}{|c|}{ Demonstration skills }} & \multicolumn{2}{|c|}{ Pre } & \multicolumn{2}{|c|}{ Post } & \multicolumn{2}{|c|}{ Follow-up } \\
\hline & & \multirow{2}{*}{$\begin{array}{l}\mathbf{N} \\
11\end{array}$} & \multirow{2}{*}{$\begin{array}{r}\% \\
25.6\end{array}$} & \multirow{2}{*}{$\begin{array}{l}\mathbf{N} \\
40\end{array}$} & \multirow{2}{*}{$\begin{array}{c}\% \\
93.0\end{array}$} & \multirow{2}{*}{$\frac{\mathbf{N}}{38}$} & \multirow{2}{*}{$\begin{array}{c}\% \\
88.4\end{array}$} \\
\hline 1 & Prepares equipment and supplies for demonstration & & & & & & \\
\hline 2 & Orients students about the objective of clinical Procedure & 26 & 60.5 & 41 & 95.3 & 40 & 93.0 \\
\hline 3 & $\begin{array}{l}\text { Discusses the expectations of the clinical experience with the } \\
\text { students prior to demonstrating procedure }\end{array}$ & 25 & 58.1 & 41 & 95.3 & 39 & 90.7 \\
\hline 4 & Provides clear visibility for each student & 23 & 53.5 & 41 & 95.3 & 40 & 93.0 \\
\hline 5 & Demonstrates clinical procedure simply & 22 & 51.2 & 40 & 93.0 & 39 & 90.7 \\
\hline 6 & Encourages students to formulate and express their own questions & 24 & 55.8 & 41 & 95.3 & 37 & 86.0 \\
\hline 7 & Assists students to apply procedures & 22 & 51.2 & 39 & 90.7 & 40 & 93.0 \\
\hline 8 & Observes students in clinical procedures re- demonstration & 26 & 60.5 & 40 & 93.0 & 40 & 93.0 \\
\hline 9 & Gives feedback to student about his/her Performance & 22 & 51.2 & 41 & 95.3 & 38 & 88.4 \\
\hline
\end{tabular}


Table 8 Describes clinical instructors' adequate performance regarding facilitation skills throughout the program. As noticed from the table, the majority (67.4\%) of CIs had highest performance at preprogram related to guides students during clinical practice while the lowest performance (25.6\%) of them was related to remains accessible to students during clinical time, which increased at post program. Most (97.7\%) of CIs had the highest performance at post program related to makes sure time is best used. However, at follow up phase, most (95.3\%) of CIs had highest performance related to gives guidance during demonstration of clinical procedures and answers students' questions clearly.

Table 8: Clinical Instructors Adequate Performance Regarding Facilitation Skills throughout the Program (N=43)

\begin{tabular}{|c|c|c|c|c|c|c|c|}
\hline \multirow{2}{*}{\multicolumn{2}{|c|}{ Facilitation skills }} & \multicolumn{2}{|c|}{ Pre } & \multicolumn{2}{|c|}{ Post } & \multicolumn{2}{|c|}{ Follow_up } \\
\hline & & \multirow{2}{*}{$\begin{array}{l}\mathbf{N} \\
25\end{array}$} & \multirow{2}{*}{\begin{tabular}{|c|}
$\%$ \\
58.1
\end{tabular}} & \multirow{2}{*}{$\begin{array}{l}\mathbf{N} \\
40\end{array}$} & \multirow{2}{*}{$\begin{array}{c}\% \\
93.0 \\
\end{array}$} & \multirow{2}{*}{$\begin{array}{l}\mathbf{N} \\
41 \\
\end{array}$} & \multirow{2}{*}{$\begin{array}{c}\% \\
95.3 \\
\end{array}$} \\
\hline 1. & $\begin{array}{l}\text { Gives guidance during demonstration of } \\
\text { clinical procedures }\end{array}$ & & & & & & \\
\hline 2. & $\begin{array}{l}\text { Allows students to learn from their } \\
\text { mistakes }\end{array}$ & 28 & 65.1 & 41 & 95.3 & 40 & 93.0 \\
\hline 3. & $\begin{array}{l}\text { Remains accessible to students during } \\
\text { clinical time }\end{array}$ & 11 & 25.6 & 38 & 88.4 & 39 & 90.7 \\
\hline 4. & Answers students' questions clearly & 19 & 44.2 & 41 & 95.3 & 41 & 95.3 \\
\hline 5. & Guides students during clinical practice & 29 & 67.4 & 41 & 95.3 & 40 & 93.0 \\
\hline 6. & Makes sure time is best used & 25 & 58.1 & 42 & 97.7 & 40 & 93.0 \\
\hline
\end{tabular}

Table 9 Shows clinical instructors' adequate performance regarding assessment and coordination skills throughout the program. As indicated from the table, the majority $(69.8 \%)$ of CIs had highest performance at preprogram related to sets goals for clinical day, which increased at post program to $(97.7 \%)$ and slightly declined at follow up to reach $(90.7 \%)$. While the highest percentage (95.3\%) of CIs had highest performance related to identifies each student's ability to demonstrate procedure and provides students with an opportunity to organize their clinical time at follow up phase.

Table 9: Clinical Instructors Adequate Performance Regarding Assessment and Coordination Skills throughout the $\operatorname{Program}(\mathrm{N}=43)$

\begin{tabular}{|l|l|c|c|c|c|c|c|}
\hline \multicolumn{2}{|c|}{ Assessment and coordination skills } & \multicolumn{2}{c|}{ Pre } & \multicolumn{2}{|c|}{ Post } & \multicolumn{2}{c|}{ Follow-up } \\
\cline { 3 - 8 } & $\mathbf{N}$ & $\mathbf{\%}$ & $\mathbf{N}$ & $\mathbf{\%}$ & $\mathbf{N}$ & $\mathbf{\%}$ \\
\hline $\mathbf{1 .}$ & Assesses students' understanding of the clinical procedures & 27 & 62.8 & 41 & 95.3 & 40 & 93.0 \\
\hline $\mathbf{2 .}$ & Identifies each student's ability to demonstrate procedure & 17 & 39.5 & 41 & 95.3 & 41 & 95.3 \\
\hline $\mathbf{3 .}$ & Sets goals for clinical day & 30 & 69.8 & 42 & 97.7 & 39 & 90.7 \\
\hline $\mathbf{4 .}$ & Ensures that students identify priorities of patient Care & 19 & 44.2 & 40 & 93.0 & 40 & 93.0 \\
\hline $\mathbf{5 .}$ & Helps students recognize the need for more data & 25 & 58.1 & 42 & 97.7 & 42 & 97.7 \\
\hline $\mathbf{6 .}$ & $\begin{array}{l}\text { Discusses with students unscheduled events which occur } \\
\text { occasionally at clinical day }\end{array}$ & 28 & 65.1 & 40 & 93.0 & 38 & 88.3 \\
\hline $\mathbf{7 .}$ & Provides students with an opportunity to organize their clinical time & 27 & 62.8 & 41 & 95.3 & 41 & 95.3 \\
\hline $\mathbf{8 .}$ & $\begin{array}{l}\text { Ensures that student is assigned the appropriate client to meet } \\
\text { clinical learning objectives }\end{array}$ & 29 & 67.4 & 39 & 90.7 & 39 & 90.7 \\
\hline $\mathbf{9 .}$ & $\begin{array}{l}\text { Expresses with students concerns about upcoming clinical } \\
\text { experience }\end{array}$ & 17 & 39.5 & 40 & 93.0 & 40 & 93.0 \\
\hline
\end{tabular}

Table 10 Describes clinical instructors' adequate performance regarding supporting skills throughout the program. As noticed from the table, the majority $(74.4 \%)$ of CIs had the highest performance at preprogram 
related to supports student during clinical training, while (95.3\%) of them had highest performance at post program related to supports student during clinical training, answers students' question clearly and encourages competent performance of students. At follow-up the majority (95.3\%) of CIs had highest performance related to answers students' question clearly.

Table 10: Clinical Instructors Adequate Performance Regarding Supporting Skills throughout the Program (N=43)

\begin{tabular}{|c|c|c|c|c|c|c|c|}
\hline \multirow{2}{*}{\multicolumn{2}{|c|}{ Supporting Skills }} & \multicolumn{2}{|c|}{ Pre } & \multicolumn{2}{|c|}{ Post } & \multicolumn{2}{|c|}{ Follow-up } \\
\hline & & $\mathbf{N}$ & $\%$ & $\mathbf{N}$ & $\%$ & $\mathbf{N}$ & $\%$ \\
\hline 1. & Answers students' question clearly & 19 & 44.2 & 41 & 95.3 & 41 & 95.3 \\
\hline 2. & $\begin{array}{l}\text { Coordinates student training activities with nursing } \\
\text { activities }\end{array}$ & 31 & 72.1 & 40 & 93.0 & 39 & 90.7 \\
\hline 3. & Supports student during clinical training & 32 & 74.4 & 41 & 95.3 & 38 & 88.3 \\
\hline 4. & Encourages competent performance of students & 26 & 60.5 & 41 & 95.3 & 40 & 93.0 \\
\hline 5. & Solves students' problem related to clinical & 27 & 62.8 & 39 & 90.7 & 30 & 69.7 \\
\hline 6. & $\begin{array}{l}\text { Encourages students to communicate effectively with } \\
\text { health team }\end{array}$ & 24 & 55.8 & 28 & 65.1 & 29 & 67.4 \\
\hline
\end{tabular}

Table 11 Displays clinical instructors' adequate performance regarding training skills throughout the program. As noticed from the table, the majority $(72.1 \%)$ of FAs had highest performance at preprogram related to allow students to lead clinical round, while all of them $(100 \%)$ had highest performance at post program related to demonstrate procedures for student if required which slightly declined at follow up phase to reach $(97.7 \%)$.

Clinical Instructors Adequate Performance Regarding Training Skills throughout the Program (N=43)

\begin{tabular}{|c|c|c|c|c|c|c|c|}
\hline \multirow{2}{*}{\multicolumn{2}{|c|}{ Training Skills }} & \multicolumn{2}{|c|}{ Pre } & \multicolumn{2}{|c|}{ Post } & \multicolumn{2}{|c|}{ Follow-up } \\
\hline & & \multirow{2}{*}{$\begin{array}{c}\mathbf{N} \\
25\end{array}$} & \multirow{2}{*}{$\begin{array}{c}\% \\
58.1\end{array}$} & \multirow{2}{*}{$\begin{array}{l}\mathbf{N} \\
40\end{array}$} & \multirow{2}{*}{$\frac{\mathbf{\%}}{93.0}$} & \multirow{2}{*}{$\begin{array}{l}\mathbf{N} \\
39\end{array}$} & \multirow{2}{*}{$\begin{array}{c}\% \\
90.7\end{array}$} \\
\hline 1. & $\begin{array}{l}\text { Discusses the expectations of clinical practice with } \\
\text { student prior to clinical practice }\end{array}$ & & & & & & \\
\hline 2. & Demonstrates procedures for student if required & 28 & 65.1 & 43 & 100.0 & 43 & 97.7 \\
\hline 3. & Assists student in clinical proced ${ }_{\text {ures }}$ hen required & 26 & 60.5 & 41 & 95.3 & 40 & 93.0 \\
\hline 4. & Asks questions relevant to clinical practice & 23 & 53.5 & 40 & 93.0 & 41 & 95.3 \\
\hline 5. & Guides group discussion when needed & 27 & 62.8 & 40 & 93.0 & 40 & 93.0 \\
\hline 6. & Allows students to lead clinical round & 31 & 72.1 & 37 & 86.0 & 35 & 81.3 \\
\hline
\end{tabular}

Table 12 Reveals clinical instructors' adequate performance regarding interpersonal relation and communication skills throughout the program. As indicated from the table, most $(65.1 \%)$ of faculty assistants had highest performance at preprogram related to communicate in suitable manner. All (100\%) of CIs had highest performance at post program related to demonstrates warmth and patience in interpersonal relationship with student. However, at follow up most $(97.7 \%)$ of CIs had the highest performance related to encourage a climate of mutual respect. 
Table 12: Clinical Instructors Adequate Performance Regarding Interpersonal Relations and Communication Skills throughout the Program (N=43)

\begin{tabular}{|c|c|c|c|c|c|c|c|}
\hline & & & & & & & \\
\hline & tersonal rerations and Commumcation SKmis & . & 0 & & & & \\
\hline 1. & Communicates in suitable manner & 28 & 65.1 & 40 & 93.0 & 39 & 90.7 \\
\hline 2. & $\begin{array}{l}\text { Assess communication between students and } \\
\text { patient }\end{array}$ & 27 & 62.8 & 40 & 93.0 & 39 & 90.7 \\
\hline 3. & Deals with other colleagues with respect & 19 & 44.2 & 41 & 95.3 & 40 & 93.0 \\
\hline 4. & $\begin{array}{l}\text { Maintains smooth and good relationship with } \\
\text { health team member }\end{array}$ & 27 & 62.8 & 40 & 93.0 & 40 & 93.0 \\
\hline 5. & Encourages a climate of mutual respect & 25 & 58.1 & 41 & 95.3 & 42 & 97.7 \\
\hline 6. & $\begin{array}{l}\text { Demonstrates warmth and patience in } \\
\text { interpersonal relationship with student }\end{array}$ & 25 & 58.1 & 43 & 100.0 & 38 & 88.4 \\
\hline 7. & Accepts different opinions of students & 25 & 58.1 & 42 & 97.7 & 41 & 95.3 \\
\hline 8. & Listens carefully to students & 20 & 46.5 & 39 & 90.7 & 37 & 86.0 \\
\hline 9. & $\begin{array}{l}\text { Corrects student mistakes without embarrassing } \\
\text { Them }\end{array}$ & 19 & 44.2 & 39 & 90.7 & 39 & 90.7 \\
\hline 10. & Does not criticize students in front of others & 20 & 46.5 & 40 & 93.0 & 39 & 90.7 \\
\hline
\end{tabular}

Table 13 Displays clinical instructors' adequate performance regarding creates stimulating learning environment throughout the program. As noticed from the table, three fifth $(60.5 \%)$ of CIs had highest performance at preprogram related to gives student the opportunities to apply theoretical content in clinical practice, while in post program the majority $(95.3 \%)$ of them had highest performance related to encourages student to participate actively in word activities, facilitates interaction between students and nurse, ensures adequate light, ensures appropriate ventilation. However, at follow-up most $(95.3 \%)$ of CIs had the highest performance was related to ensures that facilities adequately accommodate the needs of the students and ensures that external noise level does not interfere with learning.

Table 13: Clinical Instructors Adequate Performance Regarding Create Stimulating Learning Environment throughout the Program ( $N=43$ )

\begin{tabular}{|c|c|c|c|c|c|c|c|}
\hline \multirow{2}{*}{\multicolumn{2}{|c|}{ Create Stimulating Learning Environment }} & \multicolumn{2}{|c|}{ Pre } & \multicolumn{2}{|c|}{ Post } & \multicolumn{2}{|c|}{ Follow- up } \\
\hline & & \multirow{2}{*}{$\begin{array}{c}\mathbf{N} \\
17\end{array}$} & \multirow{2}{*}{\begin{tabular}{|c|}
$\%$ \\
39.5 \\
\end{tabular}} & \multirow{2}{*}{$\begin{array}{l}\mathbf{N} \\
39 \\
\end{array}$} & \multirow{2}{*}{\begin{tabular}{|c|}
$\%$ \\
90.7
\end{tabular}} & \multirow{2}{*}{$\begin{array}{c}\mathbf{N} \\
41 \\
\end{array}$} & \multirow{2}{*}{\begin{tabular}{|c|}
$\%$ \\
95.3 \\
\end{tabular}} \\
\hline 1. & $\begin{array}{l}\text { Ensures that facilities adequately accommodate the needs of the } \\
\text { students }\end{array}$ & & & & & & \\
\hline 2. & $\begin{array}{l}\text { Ensures the availability of adequate space to accommodate } \\
\text { student activities }\end{array}$ & 18 & 41.9 & 40 & 93.0 & 39 & 90.7 \\
\hline 3. & Ensures that external noise level does not interfere with learning & 21 & 48.8 & 39 & 90.7 & 41 & 95.3 \\
\hline 4. & Ensures appropriate ventilation & 13 & 30.2 & 41 & 95.3 & 40 & 93.0 \\
\hline 5. & Ensures adequate light & 21 & 48.8 & 41 & 95.3 & 39 & 90.7 \\
\hline 6. & Ensures there is enough patients for each student & 19 & 44.2 & 38 & 88.4 & 38 & 88.4 \\
\hline 7. & Determines mutual responsibilities of nurses and students & 22 & 51.2 & 40 & 93.0 & 39 & 90.7 \\
\hline 8. & Facilitates interaction between students and nurse & 15 & 34.9 & 41 & 95.3 & 39 & 90.7 \\
\hline 9. & $\begin{array}{l}\text { Gives student the opportunities to apply theoretical content in } \\
\text { clinical practice }\end{array}$ & 26 & 60.5 & 39 & 90.7 & 39 & 90.7 \\
\hline 10. & Encourages student to participate actively in word activities & 21 & 48.8 & 41 & 95.3 & 39 & 90.7 \\
\hline 11. & Acts as a role model for positive behaviour & 20 & 46.5 & 39 & 90.7 & 40 & 93.0 \\
\hline
\end{tabular}


Table 14 demonstrates clinical instructors" adequate performance regarding evaluation skills throughout the program. As indicated from the table, most $(93.0 \%)$ of CIs had highest performance at preprogram related to evaluate students' clinical performance. However, at post program the majority $(100 \%$ and $97.7 \%)$ of CIs had highest performance related to evaluate student's clinical performance, gives feedback in private if needed, provides suggestion for students' performance improvement and demonstrates objectivity and fairness in evaluation. While the highest percentage $(100 \%$ and $97.7 \%)$ of CIs had highest performance related to determines weak points of student performance for each student, discuss negative points of student performance with students, evaluates student's clinical performance, demonstrates objectivity and fairness in evaluation and provides suggestion for students' performance improvement at follow up phase.

Table 14: Clinical Instructors Adequate Performance' Regarding Evaluation Skills throughout the Program (N=43)

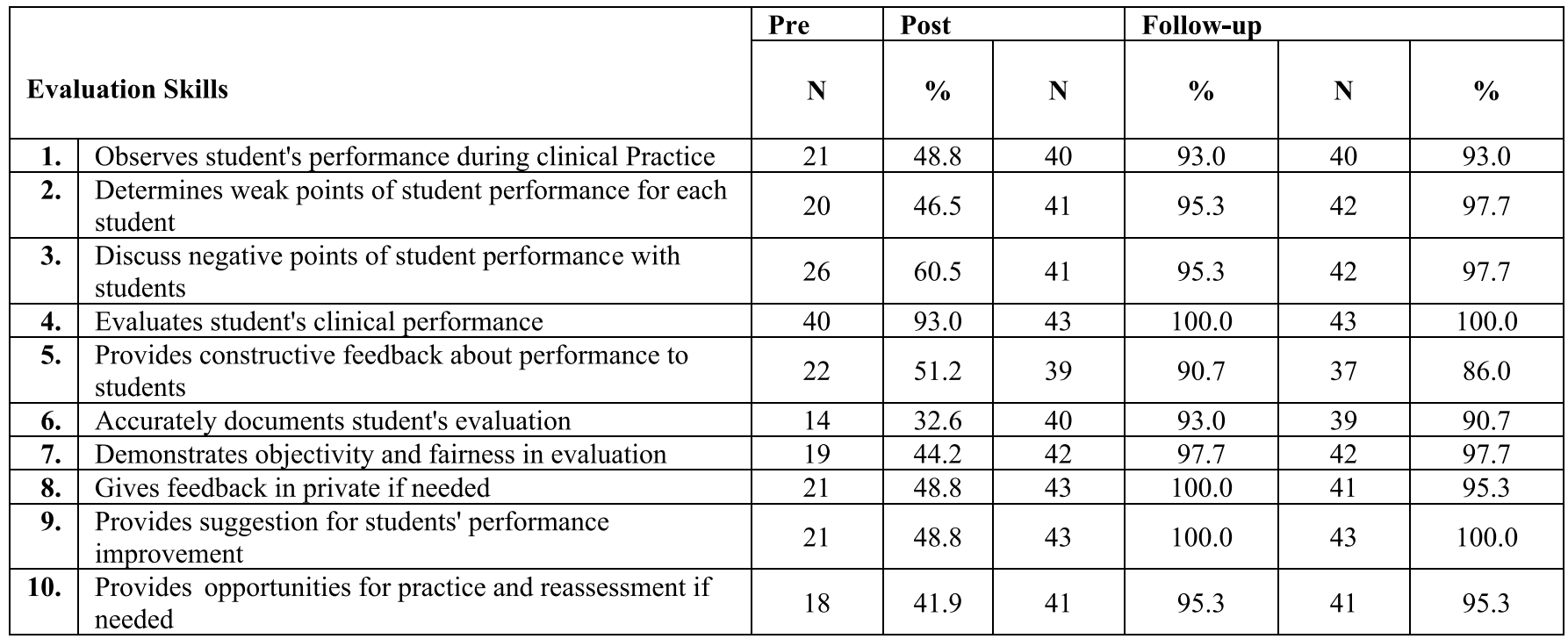

Table 15 describes clinical instructors' adequate performance regarding critical thinking skills throughout the program. As noticed from the table, near to two fifth $(37.2 \%)$ of CIs had highest performance at preprogram related to provide students with case study and encourages student to use clinical log, while in post program most $(95.3 \%)$ of them had highest performance related to uses small group discussion during clinical practice and asks vital question that stimulate student critical thinking ,however at follow-up the majority $93.0 \%$ of CIs had highest performance related to uses bed side teaching during clinical practice, uses small group discussion during clinical practice and provides students with case study.

Table 15: Clinical Instructors Adequate Performance Regarding Critical Thinking Skills throughout the Program $(N=43)$

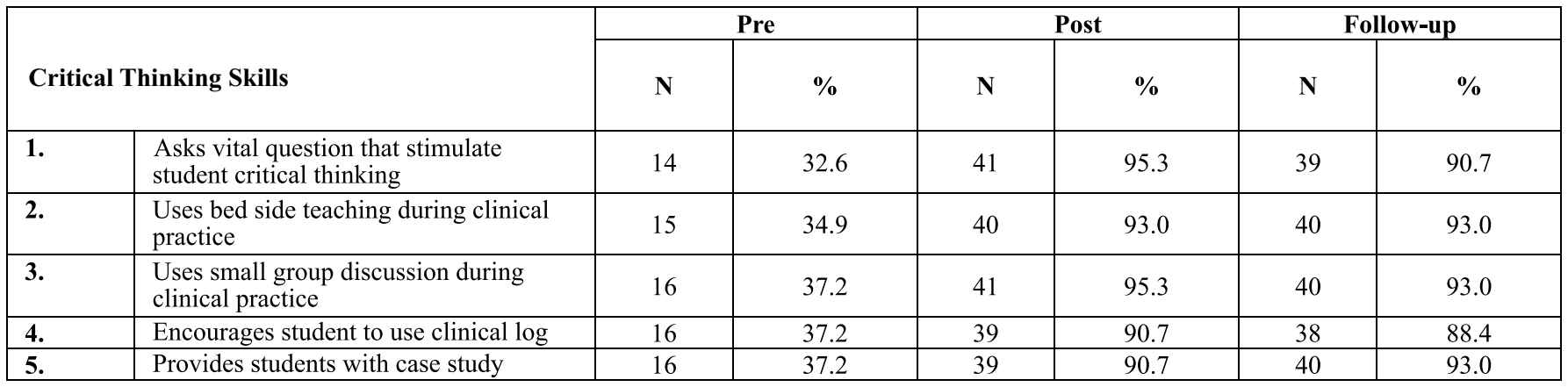


Table 16 displays the mean score of clinical instructors' total performance throughout the program (pre, post \& follow up). As observed from the table, there was a statistically significant difference between mean scores of clinical instructors in relation to their performance at pre, post and follow up. Mean score at preprogram was $(46.6 \pm 4.62)$ which increased at post program to $(82.4 \pm 2.8)$ and slightly declined at follow-up to $(82.1 \pm 2.93)$.

Table 16: Total Mean Scores of Clinical Instructors Practice (Pre-Post-Follow-Up) Intervention Program (N=50)

\begin{tabular}{|c|c|c|c|c|c|c|c|}
\hline \multirow{2}{*}{ Total performance } & \multicolumn{2}{|c|}{$\begin{array}{c}\text { Pre program } \\
\text { implementation }\end{array}$} & \multicolumn{2}{|c|}{$\begin{array}{l}\text { Post program } \\
\text { Implementation }\end{array}$} & \multicolumn{2}{|c|}{$\begin{array}{c}\text { Follow up } \\
\text { program }\end{array}$} & \multirow{2}{*}{\begin{tabular}{|l} 
F test \\
$P$ value
\end{tabular}} \\
\hline & Mean & SD & Mean & SD & Mean & SD & \\
\hline \multirow[b]{2}{*}{ Personal attributes } & \multirow{2}{*}{9.785} & \multirow{2}{*}{1.957} & \multirow{2}{*}{15.837} & \multirow{2}{*}{1.173} & \multirow{2}{*}{15.860} & \multirow{2}{*}{1.166} & 429.88 \\
\hline & & & & & & & $<0.001 * * *$ \\
\hline \multirow{3}{*}{ Demonstration skills } & \multirow{3}{*}{4.674} & \multirow{3}{*}{1.442} & \multirow{3}{*}{8.4186} & \multirow{3}{*}{0.73136} & \multirow{3}{*}{8.4419} & \multirow{3}{*}{0.73363} & 195.34 \\
\hline & & & & & & & \\
\hline & & & & & & & $<0.001 * * *$ \\
\hline \multirow[b]{2}{*}{ Facilitation skills } & \multirow{2}{*}{3.418} & \multirow{2}{*}{1.159} & \multirow{2}{*}{5.790} & \multirow{2}{*}{0.411} & \multirow{2}{*}{5.674} & \multirow{2}{*}{0.521} & 150.61 \\
\hline & & & & & & & $<0.001 * * * *$ \\
\hline \multirow{3}{*}{$\begin{array}{l}\text { Assessment and } \\
\text { coordination skills }\end{array}$} & \multirow{3}{*}{5.093} & \multirow{3}{*}{1.287} & & & & & 259.34 \\
\hline & & & 8.488 & 0.702 & 8.488 & 0.702 & \\
\hline & & & & & & & $<0.001 * * *$ \\
\hline & & & & & & & 57.23 \\
\hline Supportive skills & & & & & & & $<0.001 * * *$ \\
\hline & & & & & & & 90.50 \\
\hline Training skills & 3.000 & 1.133 & 4.720 & 0.503 & 4.744 & 0.492 & \\
\hline & & & & & & & $<0.001 * * *$ \\
\hline Interpersonal relation and & 5.465 & 1593 & 9.395 & 0728 & 9279 & 0734 & 179.60 \\
\hline communication skills & & & & & & & $<0.001 * * *$ \\
\hline Creating stimulating & 4.953 & 1.526 & 10.186 & 0.852 & 10.139 & 0.861 & 379.80 \\
\hline learning environment & & & & & & & $<0.001 * * *$ \\
\hline Fulnation alillo & 4767 & 1342 & 0511 & $070 ?$ & 0465 & 0735 & 416.78 \\
\hline 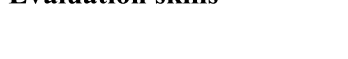 & & & & & & & $<0.001 * * *$ \\
\hline & 1767 & 1211 & 1651 & 0520 & 1671 & 0521 & 161.91 \\
\hline Critical tninking skins & 1.707 & 1.211 & 4.031 & 0.523 & 4.014 & 0.021 & $<0.001 * * *$ \\
\hline & & & & & & & 1941.28 \\
\hline Total & 40.000 & 4.020 & 02.410 & 2.003 & 02.139 & 2.952 & $<0001 * * *$ \\
\hline & & & & & & & 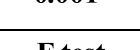 \\
\hline Total performance & $\begin{array}{r}\mathbf{P} \\
\mathbf{i m} \\
\end{array}$ & $\begin{array}{l}\text { am } \\
\text { ation }\end{array}$ & $\begin{array}{r}\mathbf{P r} \\
\mathbf{I m}\end{array}$ & $\begin{array}{l}\text { gram } \\
\text { ntation }\end{array}$ & & $\begin{array}{l}\mathrm{v} \text { up } \\
\text { am }\end{array}$ & F test \\
\hline 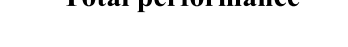 & Mean & SD & Mean & SD & Mean & SD & $P$ value \\
\hline & & & & & & & 429.88 \\
\hline Personal attributes & 9.785 & 1.957 & 15.837 & 1.173 & 15.860 & 1.166 & \\
\hline & & & & & & & $<0.001 * * *$ \\
\hline
\end{tabular}




\begin{tabular}{|c|c|c|c|c|c|c|c|}
\hline \multirow{2}{*}{ Demonstration skills } & \multirow{2}{*}{4.674} & \multirow{2}{*}{1.442} & \multirow{2}{*}{8.4186} & \multirow{2}{*}{0.73136} & \multirow{2}{*}{8.4419} & \multirow{2}{*}{0.73363} & 195.34 \\
\hline & & & & & & & $<0.001 * * *$ \\
\hline \multirow{3}{*}{ Facilitation skills } & \multirow{3}{*}{3.418} & \multirow{3}{*}{1.159} & \multirow{3}{*}{5.790} & \multirow{3}{*}{0.411} & \multirow{3}{*}{5.674} & \multirow{3}{*}{0.521} & 150.61 \\
\hline & & & & & & & \\
\hline & & & & & & & $<0.001 * * *$ \\
\hline \multirow{2}{*}{$\begin{array}{l}\text { Assessment and } \\
\text { coordination skills }\end{array}$} & \multirow{2}{*}{5.093} & \multirow{2}{*}{1.287} & \multirow{2}{*}{8.488} & \multirow{2}{*}{0.702} & \multirow{2}{*}{8.488} & \multirow{2}{*}{0.702} & 259.34 \\
\hline & & & & & & & $<0.001 * * *$ \\
\hline \multirow{3}{*}{ Supportive skills } & \multirow{3}{*}{3.697} & \multirow{3}{*}{1.145} & \multirow{3}{*}{5.418} & \multirow{3}{*}{0.763} & \multirow{3}{*}{5.372} & \multirow{3}{*}{0.690} & 57.23 \\
\hline & & & & & & & \\
\hline & & & & & & & $<0.001 * * *$ \\
\hline \multirow{3}{*}{ Training skills } & \multirow{3}{*}{3.000} & \multirow{3}{*}{1.133} & \multirow{3}{*}{4.720} & \multirow{3}{*}{0.503} & & & 90.50 \\
\hline & & & & & & & $0001 * * *$ \\
\hline & & & & & & & $<0.001 \cdots$ \\
\hline Interpersonal relation and & 5,465 & 1593 & 9395 & 0728 & 9279 & 0734 & 179.60 \\
\hline communication skills & & & & & & & $<0.001 * * *$ \\
\hline Creating stimulating & 4.953 & 1.526 & 10.186 & 0.852 & 10.139 & 0.861 & 379.80 \\
\hline learning environment & & & & & & & $<0.001 * * *$ \\
\hline & & & 0.511 & $070 ?$ & $0: 165$ & 0725 & 416.78 \\
\hline Evaluation skills & $4 . / 6 /$ & 1.342 & 9.511 & 0.102 & 9.465 & 0.135 & $<0.001 * * *$ \\
\hline . & 1767 & 1211 & 1651 & $0-520$ & 474 & 0.521 & 161.91 \\
\hline & & & & & & & $<0.001 * * *$ \\
\hline & & & & & & & 1941.28 \\
\hline Total & 46.666 & 4.620 & 82.418 & 2.863 & 82.139 & 2.932 & \\
\hline & & & & & & & $<0.001 * * *$ \\
\hline
\end{tabular}

Table 17 reveals the association between total clinical instructors' performance (pre and post) intervention. As observed from the table, there were significant differences between mean performance of the clinical instructors in pre and post intervention program.

Table 17: Association Between Total Clinical Instructors Performance (Pre-Post) Intervention (N=43)

\begin{tabular}{|c|c|c|c|c|c|c|}
\hline \multirow{2}{*}{ Item } & \multirow{2}{*}{ Pre- practice } & \multirow{2}{*}{ Post- practice } & \multicolumn{2}{|c|}{ Confidence interval (CI) } & \multirow{2}{*}{$\boldsymbol{t}$ test } & \multirow{2}{*}{$\boldsymbol{P}$ test } \\
\cline { 4 - 7 } & & & Lower & Upper & & \\
\hline Mean & $46.666 \pm$ & $82.139 \pm$ & 34.108 & 37.272 & 45.55 & $<0.001^{* * *}$ \\
& 4.620 & 2.932 & & & & \\
\hline $\begin{array}{c}\text { Effectivness } \\
\text { (mean difference) }\end{array}$ & & & & & & \\
\hline
\end{tabular}


Table 18 reveals the association between total clinical instructors' performance (pre and post) intervention. As observed from the table, there were significant differences between mean performance of the clinical instructors in pre and follow-up intervention program.

Table 18: Association Between Total Clinical Instructors Performance (Pre-Follow-Up) Intervention (N=43)

\begin{tabular}{|c|c|c|c|c|c|c|}
\hline \multirow{2}{*}{ Item } & \multirow{2}{*}{ Pre-practice } & \multirow{2}{*}{ follow up } & \multicolumn{2}{|c|}{ Confidenc e interval ( CI) } & \multirow{2}{*}{$t$-test } & \multirow{2}{*}{$P$-value } \\
\hline & & & Lower & Upper & & \\
\hline Mean & $\begin{array}{c}46.666 \pm \\
4.620\end{array}$ & $\begin{array}{c}74.96 \pm \\
11.96\end{array}$ & 33.796 & 37.060 & 43.84 & $<0.001 * * *$ \\
\hline $\begin{array}{c}\text { Effectiveness } \\
\text { (mean difference) }\end{array}$ & \multicolumn{6}{|c|}{$35.428 \pm 5.236$} \\
\hline
\end{tabular}

Figure 2 show that the distribution of total practice scores represented by $25^{\text {th }}, 50^{\text {th }}$ (median), $75^{\text {th }}$ percentiles, minimum, maximum among the studied clinical instructors was significantly higher in post and follow-up post guidelines phases in comparison to preguidelines phases.

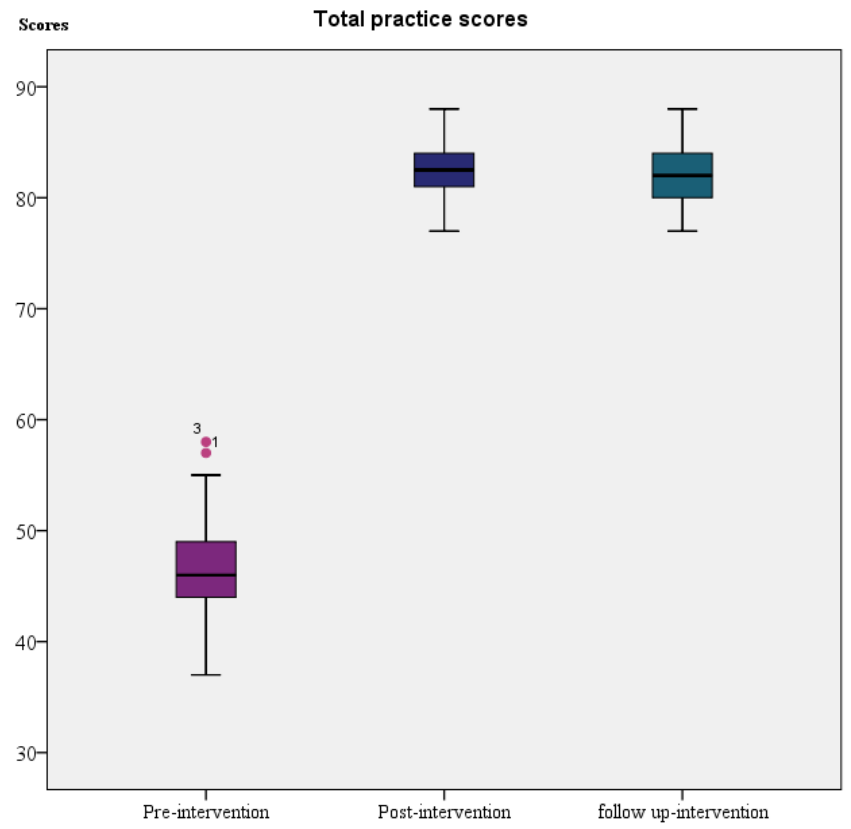

Figure 2 Distribution of total practice scores (pre-postfollow up) among the studied clinical instructors represented by $25^{\text {th }}, 50^{\text {th }}$ (median), $75^{\text {th }}$ percentiles, minimum, maximum and outlier values $(n=43)$.

Table 19 shows the relation between clinical instructors' characteristics and their skills level. As noted from the table, there were statistically significant relations between faculty assistants' characteristics (age, academic position \& specialty) and their performance level.
Table 19: Association between Demographic Data and their Performance Level $(\mathrm{N}=43)$

\begin{tabular}{|c|c|c|}
\hline \multirow{2}{*}{ Clinical instructors' characteristics } & \multicolumn{2}{|c|}{ Total performance } \\
\hline & $t$ - test & $P$ value \\
\hline \multicolumn{3}{|l|}{ Age } \\
\hline$<26$ & \multirow{3}{*}{$\begin{array}{c}\mathrm{F} \\
(3.520)\end{array}$} & \multirow{3}{*}{$0.039 *$} \\
\hline $26-30$ & & \\
\hline$>30$ & & \\
\hline \multicolumn{3}{|l|}{ Years of experience } \\
\hline$<1$ & \multirow{4}{*}{$\begin{array}{c}F \\
(2.446)\end{array}$} & \multirow{4}{*}{0.078} \\
\hline $1:<3$ & & \\
\hline $3:<5$ & & \\
\hline $5:<=7$ & & \\
\hline \multicolumn{3}{|l|}{ Academic position } \\
\hline Demonstrator & \multirow{2}{*}{$\begin{array}{c}t \\
(2.686) \\
\end{array}$} & \multirow{2}{*}{$0.01 *$} \\
\hline Assistant lecturer & & \\
\hline \multicolumn{3}{|l|}{ Specialty } \\
\hline Medical Surgical Nursing & \multirow{5}{*}{$\begin{array}{c}\mathrm{F} \\
(2.744)\end{array}$} & \multirow{5}{*}{$0.41 *$} \\
\hline Pediatric Nursing & & \\
\hline $\begin{array}{l}\text { Obstetric and Gynecological } \\
\text { Nursing }\end{array}$ & & \\
\hline $\begin{array}{l}\text { Psychiatric and Mental Health } \\
\text { Nursing }\end{array}$ & & \\
\hline Nursing Administration & & \\
\hline
\end{tabular}

\section{DISCUSSION}

Regarding the training needs of clinical instructors related to clinical teaching skills, the findings of the present study displayed that, the majority of clinical instructors mentioned that they need most of training topics. The highest percentage of needs was related to role of clinical trainer and clinical teaching strategies and the lowest percentage was related to concept of adult. All items of need assessment scored $80.0 \%$ or more included in the study. This result may be due to the CIs are primarily concerned with learning and improving their performance. 
Regarding performance of clinical instructors related to personal attributes, the findings of present study displayed that in preprogram phase all of CIs had highest performance related to physically capable and mentally alert and the percentage remained the same in post and follow-up phase, while the majority of them had highest performance related to face students while speaking and has good sense of humor. At post program the most of them had highest performance related to clear easily hear voice, exhibits facial gestures or expressions, flexible and has patient in clinical area with students. At follow-up, the highest percentage of CIs had highest performance related to speak at an appropriate space and be patient in clinical area with students.

The findings of the present study was consistent with the results of Badran, (2014), who reported that there was statistical improvement in faculty assistants' personal attributes after the program implementation. On the same aspect, Mahfouz (2011) revealed that there was a highly statistically significant improvement in the assistant teaching staff personal characteristics after program.

On the other hand, Labrague et al., (2019) reported that among the different teaching characteristics, instructors' 'personality' was identified as the least important nursing faculty characteristic. This teaching domain contains attitudes, attributes, quality and character traits not specifically associated with teaching or nursing such as having a sense of humor, being patient, being sincere, being energetic and being enthusiastic. Similarly, Ismail et al., (2016) revealed that faculty 'personal attributes' were also identified as the least important nursing faculty characteristic among nursing students 23. Studies among Arab nursing students yielded similar findings, as items reflecting the personal characteristics of the nursing faculty were identified as least important in the learning process of the nursing students.

On the same line, Collier (2018) mentioned that ten of the 37 studies identified personality traits necessary for a teacher to be an effective nursing clinical instructor. Knox \& Mogon (1985) defined personality as "the totality of the individual's attitudes, emotional tendencies, and character traits, which are not specifically related to teaching, nursing, or interpersonal relationship, but may affect all three). Among the students in this study, approachability was the highest rated characteristic. Also, indicated that an effective instructor is supportive, helpful, approachable, respectful, caring, enthusiastic, encouraging, open to suggestions, a good communicator and able to make students feel confident.

A more recent study by Rowbotham \& Owen (2015) found that self-efficacy increased with faculty who communicated expectations, observed frequently and suggested ways to improve. Croxon \& Maginnis (2009) mixed-method study also identified a constructive learning environment as one that had a friendly and approachable staff/instructor. Kube's (2010) confirmed approachability as the behavior that had the greatest influence on learning.

Similarly, the results reported by Ali (2012) revealed that the nursing students considered the personality traits of clinical teacher as the fourth factors that effect on their behavior in the clinical settings.

Moreover, the result of Asfour \& El-Soussi (2011) mentioned that the students reported that clinical instructors' body language influences their performance. Students, noting that they needed their clinical instructors' attention and care, also thought that empathy was an important feature. They wanted the clinical instructors to appreciate them when they did well and added that this appreciation would motivate them.

In this respect, Mousa et al., (2012) in the study done for developing standards for the selection of an effective clinical practical setting for student, reported that most of the jury group has agreed upon personalization standard especially in relation to the trainer having individual conversations with students, and trainers should changing her/his style to help students.

As regards demonstration, the result of the present study revealed that three fifth of CIs had highest performance at preprogram related to orients students about the objective of clinical Procedure, while the majority of them had the highest performance related to orients students about the objective of clinical procedures and gives feedback to student about his performance at post program. However, at follow up the majority of CIs had highest performance related to orients students about the objective of clinical procedure and observes students in clinical procedures.

This result was supported by Collier (2018), who mentioned that four studies conducted within the past 10 years ranked nursing competency as a top priority. 
Similarly, Hou, Zhu \& Zheng., (2010) studied 237 nursing faculty members, students and administrators from six colleges in China. This study performed psychometric measures to create the Clinical Nursing Faculty Competence Inventory scale. One study compared competencies by first, second-and third-year undergraduate nursing students $(\mathrm{N}=135)$ (Lovic et al., 2014). The study identified second, and third year nursing students had higher expectations of clinical faculty competencies. This study concluded the quality of clinical practice depended on the faculty competencies.

On the same vein, Khan et al., (2012), mixed-method study, 228 students and mentors in the United Kingdom evaluated the effectiveness of practice educators, students and mentors. The results linked effectiveness to the instructor's credibility, and had consistent results identifying "demonstration" as most effective.

The findings are consistent with Badran (2014), who reported that the highest performance of FAs at pre program was related to orients student about the objective of clinical procedure, while at post program the highest performance was related to give feedback to student about his/ her performance and orient student about the objective of clinical procedure. However, at follow up, the highest performance was related to demonstrate clinical procedure simply.

On the same line, Hayajneh (2011) reported that, the participants nursing students reported that, the clinical instructor should demonstrate clinical skills, actively participate in clinical practice, and help students to identify and make use of practice opportunities. According to this study the main effective clinical teaching characteristics as perceived by participant nursing students were the clinical instructors should ask questions relevant to clinical practice, have experience in training in the hospital, and is well informed in area of clinical practice.

Concerning Facilitation skills, the finding of present study shows that most CIs had highest performance at preprogram related to guides students during clinical practice while the lowest performance of them was related to remains accessible to students during clinical time, which increased at post program. Most of CIs had the highest performance at post program related to makes sure time is best used. However, at follow up phase, most of CIs had highest performance related to gives guidance during demonstration of clinical procedures and answers students' questions clearly.

This study finding is in agreement with Badran, (2014) reported that the faculty assistants' performance at preprogram, lowest performance was related to remain accessible to students during clinical time, which increased at post program, while at follow up phase had the highest performance related to gives guidance during demonstration of clinical procedures. Sadeghi et al., (2019) who reported that some clinical instructors leaving their students, do not spend enough time on clinical setting. They leave students on their own and do not supervise the students' clinical skills acquisition properly, this considers as an inhibitory role in the formation and development of clinical competence of the nursing students as an underlying factor.

On the same vein, Collier (2018) identifying the student-teacher connection as the most important characteristic of an effective clinical instructor, in this qualitative study Students reported that these key relationships helped increase their self-worth, selfesteem and self-confidence. This study also identified appropriate boundaries of the student-teacher relationship. Those boundaries include the fact that the relationship focused on the students' learning needs, and only personal information relevant to a learning experience was shared. Which identified several attributes of a connected instructor: being genuine, spending time with the students, providing opportunities for the student to talk and being emotionally and physically available.

On the same line, Henderson et al., (2012) founded that behaviors that facilitate learning in nursing practice and simultaneously encourage questioning in the workplace are of importance to eliminate traditional ritualistic approaches to patient care). Similarly, Jansson \& Ene, (2016) in their study on nursing students' evaluation of quality indicators during learning in clinical practice, the students found that learning things without time pressure was important; it was important that the preceptor had time to explain and had patience even when the student took a long time to perform practical work.

On the other hand, Hayajneh (2011) found in her study that, the participants thought that the clinical instructor should be always available and accessible to facilitate, offer help and guidance, make clinical work 
interesting, and encourage active and cooperative learning. Similarly, Elcigil \& Sari (2008) stated that in relation to important effective clinical teaching characteristics as perceived by participant nursing students, the majority of participant emphasized on the importance of presence of clinical instructors in training area to work with students.

This result may be due to increase numbers of students in relation to their clinical instructors, and as the clinical instructor is responsible for many students in different places at the same time. So, the clinical instructor can't be present in all training area at the same time. To promote engagement in the clinical courses, the nurse educators should be available and accessible to students, and not only for discussing an upcoming clinical evaluation but also to interact with students on a personal level.

As regards assessment and coordination skills, the findings of the present study revealed that most CIs had highest performance at preprogram related to sets goals for clinical day, which increased at post program and slightly declined at follow up phase. While the highest percentage of CIs had highest performance related to identify each student's ability to demonstrate procedure and provides students with an opportunity to organize their clinical time at follow up phase.

The previous finding was supported by Badran, (2014), who indicated that four fifths of faculty assistants had highest performance at preprogram related to sets goals for clinical day, which increased at post program and follow up intervention.

In this respect, Nazari \& Mohammadi (2015) who studied Characteristics of competent clinical instructors, the study conducted on 22 participants including 12 nursing students and 10 clinical instructors, mentioned that clinical competence has been one of the determining factors for clinical qualification. Those participants believed that a competent trainer has an active clinical presence, pays inclusive attention to patients, has clinical experience and proficiency (especially in times of crisis) and is capable of providing learning opportunities for the students by using the available facilities.

On the same line, Rowbotham et al., (2015) mentioned that clinical faculty have a pivotal role in this belief and can help students meet their goals or if they need to motivate themselves and set other realistic goals. Similarly, Polit \& Beck (2008) states that Student perception of self-efficacy is strongly related to how they feel they are meeting their goals and their ability to meet them.

In this regard, Jouybari \& Sanagoo (2009) considered clinical competence as a component of management competence and described management, clinical leadership and planning as the trainer's responsibilities. Similarly, Carlsson et al., (2009) emphasized the necessity of the first goal conversation as a starting point for the preceptors to plan and adjust their responsibilities according to the students' individual needs. It is strange that a smaller number of students had a goal conversation than a final assessment. As the assessments are structured to help the student reach the goals for the period, it is important for the student to get help and feedback from the preceptor from the beginning.

In this context, Jansson \& Ene, (2016) concluded that it was important for the students that the preceptors kept track of what level the student was on and moved forward from there in the practical learning. The students experienced it as positive when they gradually got to work more independently and could take more responsibility. According to Hallin \& Danielson (2010) if the preceptor was not aware of the students' level, there was a risk that some students had to take too much responsibility, which may even be a risk for patient safety, and some students were not allowed to do things practically, just watch while the preceptor acted; both situations lead to bad learning.

In the researcher's opinion, the result may due to the clinical instructor should working to achieve the objectives of clinical setting and this will be achieved through setting goals of clinical day because it is an effective way to increase motivation and to help students to create the changes they want. It also can be used to improve health and relationships, improve productivity at work. Goals provide direction, a sense of accomplishment and they define the students' growth and development.

As regards supporting skills, the findings of the present study revealed that the highest performance of faculty assistants at preprogram was related to supports student during clinical training, while the majority of them had highest performance at post program related to supports student during clinical training and answers students' question clearly. At follow-up the most of CIs had highest performance related to answers students' 
question clearly.

The previous finding was supported by Badran (2014) who revealed that the highest performance of faculty assistants at preprogram was related to answer student questions clearly, and at post program the highest percentage was related to coordinates students activities with nursing activities, supports student during clinical training, encourage competent performance of students, solve students' problem related to clinical practice, and encourage students to communicate effectively with health team. The highest performance at follow up was related to support students during clinical training.

In the same direction, Parvan, Hosseini \& Bagherian, (2018) reported that the behaviors that had the greatest effects on student learning included "showing enthusiasm" and "grasping what students ask." On the other hand, the least effective behaviors were "criticizing students in front of others" and "guiding students to useful nursing literature." In general, the characteristics of an effective instructor included sufficient preparedness, clinical knowledge, and skills, creating motivation in students, building appropriate relationships with students and playing a supportive role.

In this regard, Nelson (2011) suggested that the behaviors of clinical instructors needed to be effective in supporting learners' outcomes include: accessibility and availability for student concerns and questions, demonstration of procedures, organization, facilitation of discussions, provision of feedback, and role modeling.

In the same direction, Mlek (2011) reported that the study participants described positive characteristics of their clinical teachers to be: approachable, supportive, open for discussion, respectful of students' opinions, and understanding. As well, the result was supported by Hayajneh (2011), who reported that the ideal clinical instructor should be informative and resourceful, give valuable advice, provide support and encouragement to students, assist students in providing planned patient care, answer questions appropriately, and be supportive and helpful.

Moreover, the study carried out by Heydari et al., (2013) to explore experiences of Iranian students and teachers concerning student-teacher relationship in clinical nursing education. They reported that, nursing students commented that they need presence of clinical educator in a supportive atmosphere in clinical environments for better learning of skills. They experienced that if this support is available, the students will have enough self-confidence for skill accomplishment. At the same time, student's ability to carry out the skills correctly will be increased, and clinical learning goals will be achieved.

Form the researcher point of view, the student nurses are prepared to gain clinical competency and skills. To be able to meet these challenges, students need to perceive themselves as supported when in clinical practice. To provide effective student support and enhance the quality of clinical teaching, the clinical instructors should be positive role models, knowledgeable, and able to communicate effectively with other health team members.

Regarding to clinical instructors' performance related to interpersonal relations and communication skills, the finding of present study revealed that most of clinical instructors had highest performance at preprogram related to communicate in suitable manner. All of them had highest performance at post program related to demonstrate warmth and patience in interpersonal relationship with student. However, at follow up most of CIs had the highest performance related to encourage a climate of mutual respect.

This result is supported by Badran, (2014) who revealed that the highest performance of faculty assistants at preprogram was related to communicate in suitable manner, while at post program the highest performance was related to encourages a climate of mutual respect and communicate in suitable manner. However, at follow up, faculty assistants had the highest performance related to encourage a climate of mutual respect.

On this respect, Jasemi et al., (2018) who conducted a qualitative content analysis study to identify challenges in the field of clinical nurse education and founded that the effective factors in increasing students' motivation and interest in clinical education are using objective and measurable evaluation scales based on educational standards in the clinical setting; and applying competent and interested instructors who have updated knowledge and appropriate communication skills with staff and students. This can create selfesteem, motivation and interest in students and lead to a more appropriate educational environment where theoretical knowledge is applied in practice.

On the same line, the result reported by Asfour \& El-Soussi (2011) mentioned that according to focus group findings, among the most important features of 
effective clinical teaching were communication capabilities. Students noted that the communication between themselves and their clinical instructors greatly influenced the efficiency of practice hours, as the students were worried about being criticized when they asked a question. Furthermore, Elçigil \& Sari (2008), founded that instructors' attitude and communication skills played a vital role in learning and recommended that feedback should be given to student.

On this context, Lau \& Wang, (2013) mentioned that effective teaching of communication skills is critical to preparing future nurses, minimizing or eliminating miscommunication, and delivering safe and high quality care. Moreover, in the study of Elisha (2010), who reported that certified registered nurse anesthetist ranked effective communication as a highly desirable characteristic of a clinical environment that could promote effective learning.

On the other hand, the result of Clark (2008) who conducted a qualitative research study on students' perceptions of faculty, students in the study gave examples of teachers treating students unfairly; teachers behaving in demeaning and belittling ways towards students. These teachers' behaviors made students feel powerless, helpless, traumatized, angry, and upset. Similarly, in LaFauci (2009) study, nursing students felt that being exposed to clinical instructors who instilled fear and intimidation in them hindered their learning.

In the researcher's opinion, the result may due to the clinical instructor should respect the student, display a friend attitude toward student and understand students' fear. Furthermore, clinical instructors were considered as a source of support when they used interpersonal and professional interpersonal skills, when they developed relationships with students and staff members in the clinical setting. That creates a conductive environment which is essential for students learning in the clinical setting.

As regards clinical instructors' performance related to create stimulating learning environment, three fifth of CIs had highest performance at preprogram related to gives student the opportunities to apply theoretical content in clinical practice, while in post program the majority of them had highest performance related to encourages student to participate actively in word activities, facilitates interaction between students and nurse, ensures adequate light, ensures appropriate ventilation. However, at follow-up most of CIs had the highest performance was related to ensure that facilities adequately accommodate the needs of the students and ensures that external noise level does not interfere with learning.

The previous result is supported by Mahfouz (2011), who found that there were highly statistically significant improvements and differences in the performance of the Assisting teaching staff (ATS) for promoting effective and conductive CLE after intervention. The foregoing results were also consistent with Soliman et al., (2006), who reported that there was a highly statistically significant difference in the overall perception and performance of clinical instructor roles, functions and related to learning environment between pre and post program.

In a similarly study, Badran, (2014) revealed that faculty assistants had highest performance at preprogram related to ensure adequate light and ensures that facilities adequately accommodate the needs of the students. At post program, the highest performance was related to ensure that facilities adequately accommodate the needs of the students, ensure availability of adequate space to accommodate student activities, ensures that appropriate ventilation, facilitates interaction between student and nurses, give student the opportunities to apply theoretical content in clinical practice, and act as a role model for positive behavior. However, at follow up, the highest performance was related to ensure that facilities adequately accommodate the needs of the students.

On other hand, Jasemi et al., (2018) who conducted a qualitative content analysis study to identify challenges in the field of clinical nurse education concluded that the main effective factor in clinical education is the professional performance environment. The data from the participants' experiences indicates that the existence of inappropriate professional interactions and limited conformity of the clinical environment with professional standards has an inhibitory role in clinical education. Professional interactions are integral components of the clinical environment which has an essential role in increasing self-confidence and the learning motivation of nursing students. Similarly, limited educational facilities were also identified as an inhibiting factor in other clinical studies in Iran (Salimi et al., 2012). Disregard to standards of care as one of the realities prevailing in the clinical setting have been identified in various studies (Flood \& Robinia, 2014). 
In this respect, Heidari \& Norouzadeh, (2015) Clarifying the duties of students in wards also lead to increased motivation and self-esteem of those students, along with a reduction of inappropriate staff expectations. Providing suitable educational facilities, enough staffing and appropriate equipment to meet the standards in the clinical field are other strategies for reducing the gap between the theory and practice in the clinical area. Similarly, Factor (2017) mentioned that being competent and establishing a harmonious faculty-student relationship is essential for creating a learning environment wherein students feel a sense of belonging that thus enhances their learning outcomes.

In this respect, the World Health Organization WHO (2005) emphasized that the effective education offers a balance of theoretical and practical experiences to help learners develop competencies that are essential for their entering a healthcare profession and continuing to develop professionally throughout their careers. The necessary facilities, resources, and equipment should be available for teaching; the teaching should be consistent with what is being taught in other related courses.

On the same line, the result of Mousa, Adam \& Hassan, (2012), who reported that in relation equipment and supplies standard, the study result indicated the majority of jury group agreed upon the training settings should be supplied with all equipment and supplies needed for training students, while all jury groups agreed upon availability of equipment and supplies to each student.

From the researcher point of view, clinical instructors should be doing their best to make the clinical environment conductive to learning. This done through improving nurse student relationships by enhancing positive working relationship between nurses and students, demonstrating a respect for students' opinions and their learning needs. As well, they aware of the resources available to the student for effective utilization, work as a team and strive to make the student feel part of that team and create a good atmosphere of respect that reduced anxiety for the students and foster student learning.

Concerning clinical instructors' performance in relation to evaluation skills, most of CIs had highest performance at preprogram related to evaluate students' clinical performance. However, at post program the majority of them had highest performance related to evaluate student's clinical performance, gives feedback in private if needed, provides suggestion for students' performance improvement and demonstrates objectivity and fairness in evaluation. While the highest percentage of CIs had highest performance related to determines weak points of student performance for each student, discuss negative points of student performance with students, evaluates student's clinical performance, demonstrates objectivity and fairness in evaluation and provides suggestion for students' performance improvement at follow up phase.

The forgoing results were supported by Badran, (2014) who revealed that there were statistically significant differences and improvements between pre, post and follow up related to all items of evaluation skills except evaluate student's clinical performance. As well, the FAs had highest performance at pre program related to evaluate students' clinical performance and demonstrates objectivity and fairness in evaluation, while the highest performance at post program were related to observe students' performance during clinical practice, discuss negative points of students' performance with students, provide constructive feedback about performance to students, accurately document students' evaluation, and provide suggestion for students' performance improvement. However, at follow up, the highest performance was related to evaluate students' clinical performance.

On this context, Lejonqvist Eriksson \& Meretoja, (2016) who conducted study to Evaluate clinical competence during nursing education, which concluded that Evaluating clinical competence and its development during nursing education is a complex process requiring the efforts of faculty members, preceptors and students. This review shows that there is an emphasis on structured methods and with that there is a risk reducing nursing to tasks and skills. Nursing is based on science with caring as the core, and the evaluation of clinical competence should take its starting point in caring which, together with knowledge and skills, should be evident in nursing practice. It should permeate the whole nursing process and be the most important ingredient in clinical competence.

On the same line, Mahfouz (2011) revealed that, the assistant teaching staff observed clinical teaching skills in relation to their roles as assessors and evaluators in pre and immediate post program, the skills reported to be done all times was related to accuracy of documenting students' evaluation. While in follow up after three months, almost more than two thirds were related to 
conduct formative and summative evaluation. Moreover, there was a highly statistically significant improvement in the performance of the study subjects in relation to demonstrate objectivity and fairness in the evaluation. Similarly, the finding of Ali (2012) reported that student evaluation procedures ranked as the second effective clinical teaching behavior from student view.

On the other hand, Elcigil \& Yildirım, (2007) who conducted a study to determining problems experienced by student nurses in their work with clinical educators in Turkey which concluded that students asserted that they were aware that the clinical environment was an environment of learning but said that their anxiety over how they would be evaluated by their educators led to their focusing on getting good grades and passing their clinical training rather than concentrating on learning. They expressed a belief to the effect that educators were taking on the role of evaluators rather than teachers and that for this reason the clinical environment became for them only a place where higher grades had to be attained.

From the researcher point of view, clinical instructors' role is vital for the attainment of nursing students' learning needs and outcomes and for ensuring a quality learning experience. So, in order to consider development and growth during education, evaluations should be repeated, and the methods should vary to give the total picture of the clinical competence of the student. The knowledge and the ethical foundation upon which the performance is based can be evaluated by written tests, discussions or self-reflection. The students' learning process and experiences of progress and growth in clinical competence can be evaluated by portfolios, analyses of videos and evaluating self-efficacy, and thereby offer good complements to other evaluation methods.

Regarding performance of clinical instructors in relation to critical thinking, near to two fifth of CIs had highest performance at preprogram related to provide students with case study and encourages student to use clinical log, while in post program most of them had highest performance related to uses small group discussion during clinical practice and asks vital question that stimulate student critical thinking. However, at follow-up many CIs had highest performance related to uses bed side teaching during clinical practice uses small group discussion during clinical practice and provides students with case study.
This view is also supported by Chan, (2019) who provided more insights into how nursing students perceive critical thinking. Acquiring critical thinking skills could give students the ability to think comprehensively and verify the truthfulness of received information. This would help students to make sound decisions not only in relation to their nursing career, but also to their daily life. Thus, critical thinking could influence how people act and think, influencing the development of their personality and career.

Consistent with this study, Van Graan, Williams \& Koen, (2015) noted that nurses with critical thinking skills are inquisitive, flexible, and reflective when using their cognitive skills. They mentioned that, influenced by inquisitiveness, the application of critical thinking could help nurses to seek truthful information. Lin et al. (2015) also mentioned that by using critical thinking students should consider whether to believe or reject information before drawing conclusions. Reliable evidence that can be found via critical thinking is of importance in making decisions. After exploring the credibility of the available information, critical thinking could also help in the application of nursing care for patients, by helping one to make logical decisions on how to deal with problems (Dwyer et al., 2016).

Huang et al., (2015) noted that Chinese culture does not promote critical questioning; if children ask some challenging questions, they could be viewed as impolite. This could inhibit the development of their critical thinking skills. The participants made similar comments. The majority of them mentioned that an atmosphere that discourages questioning, like the spoon-feeding approach to education and traditional parenting methods, could inhibit the development of their critical thinking skills.

Consistent with this study, Badran, (2014) discovered that faculty assistants had highest performance at pre program related to use small group discussion during clinical practice, and provide student with case study. At post program, the highest performance related to ask vital questions that stimulate student critical thinking, use bed side teaching during clinical practice, and use small group discussion during clinical practice. At follow up, the highest performance was related to use small group discussion during clinical practice.

In this respect, Kan \& Stabler-Haas (2009) mentioned that an effective clinical instructor uses strategies, such as "questioning," "role playing," and "interactive discussion" 
to improve students' thinking and problem-solving skills. This is not an easy task. Being a good teacher requires much practice and learning. They found that professional attitudes, professional actions and communication skills significantly improved clinical instructor (CI) effectiveness.

The results of the current study revealed that there was a statistically significant improvement between mean scores of clinical instructors in relation to their performance at pre, post and follow up. This improvement may be due the clinical instructors' willingness to be proficient and to improve their performance, also ability of knowledge acquisition, accumulation of learned knowledge in a life, and refreshing information by using different approaches of active and participative learning during implementation of the program such as work activates and group discussion, brain storming for the faculty assistants.

Consistent with this study, Badran, (2014) who founded that here was general improvement in clinical teaching skills performance of the faculty assistants as compared to before program. The forgoing results are supported with, Abd El Aziz (2009) \& Kamal (2010) who noted that there was a marked increase in participants' performance immediately post program compared to preprogram. Furthermore, the result was supported by Mahfouz (2011), who reported that there was improvement in participants' skills immediately after the program, which decreased after three months of the program implementation. The researcher reported that these results may due be to the inability of the participants to put knowledge into practice or may be due to high workload.

The finding of present the study was consistent with Soliman et al., (2006), who showed that there was a highly significant improvement in participants' skills after the program and found gradual decline in participants' knowledge and skills two or three months after the program implementation.

The results of the current study showed that there were statistically significant relations between clinical instructors' characteristics of specialty and their knowledge level. While there were statistically significant relations between clinical instructors' characteristics (age, academic position \& specialty) and their performance level.

On the other hand, Badran, (2014) mentioned that there were statistically significant relations between faculty assistants' characteristics (age, academic position \& years of experience in clinical teaching) and their knowledge level.

The previous results are going with Badran, (2014) who revealed that there were statistically significant relations between faculty assistants' characteristics (age, academic position and years of experience in clinical teaching) and their performance level.

\section{CONCLUSION}

On the light of the main study results and answers on the research hypothesis, the study was concluded that:

The finding of the present study demonstrated that there is improvement of mean score of clinical instructors in relation to their performance at pre, post and follow up program. This confirm the research hypothesis which stated that after implementation of the training program there will be improvement in skills of clinical instructors in clinical teaching skills at clinical setting.

\section{Recommendations}

In the view of the study findings the followings are recommended:

- An orientation program for newly appointed clinical instructors about clinical teaching competencies is highly recommended.

- Provide an opportunity for newly appointed clinical instructors to discuss their clinical work, validate their decision-making, and discuss clinical issues with faculty members, who may create stimulating clinical experiences and foster the development of selfconfidence.

- Continuous assessment of clinical instructors' learning needs and monitoring their performance.

- Ongoing professional education for clinical instructors about clinical teaching skills.

- Develop a clinical teaching efficacy scale to evaluate clinical nursing instructors based on the attributes of rules and their capabilities.

- Continuous support and guidance from teaching faculty members for clinical instructors in the clinical setting in order to ensure quality of clinical teaching.

- Collaboration between the faculty and the hospital to define the mutual responsibilities/authorities and to create an environment that facilitates nursing students 
training in the hospital.

- Previous assessment of the hospital resources available for students' clinical training, which help to enhance teaching and facilitate learning.

\section{Future Researchers}

- Future studies exploring individual and academic factors that contribute to nursing students' positive perceptions of faculty teaching characteristics are warranted in the midst of the increasing diversity of students being admitted to nursing programs.

- Further researches are recommended to study other factors that affecting quality of clinical teaching.

\section{Conflict of Interests}

The authors declare that they have no conflict of interest.

\section{ACKNOWLEDGEMENT}

The authors are thankful to the institutional authority for completion of the work.

\section{REFERENCES}

Abd El Aziz, L.T. (2009). Implementation of Conflict Resolution Strategies and its Effect on Stress Level among Nursing Personnel at Banha University Hospital. Unpublished Doctorate Thesis, Faculty of Nursing, Banha University, Egypt.

Adb Rabou, H.M. (2011). Training Preceptorship Program for Qualified Nurses. Doctorate Thesis, Faculty of Nursing, Ain Shams University, Egypt, 116,195-198.

Ali, G.W. (2012). Caring and Effective Teaching Behavior of Clinical Nursing Instructors in Clinical Area as Perceived by Their Students. Journal of Education and Practice, 3(7), pp 15-26.

Asfour, A. \& El Soussi, A. (2011). A Qualitative Study of Effectiveness of Clinical Teaching. Journal of American Science, 7(7), pp 409-420.

Aziz, A.W. (2005): Developing a Standard for Teaching Staff Role. Unpublished Doctorate Thesis, Faculty of Nursing, Ain Shams University, Egypt, pp 183.

Badran, F.M. (2014). The effect of the training program on clinical teaching skills for faculty assistant. Doctorate Thesis, Faculty of Nursing, Ain Shams University, Egypt.

Baraz, S., Memarian, R. \& Vanaki, Z. (2015). Learning challenges of nursing students in clinical environments: A qualitative study in Iran. Journal of Education and Health Promotion, 4, 52.

Basavanthappa, B.T. (2012). Nursing Education (2nded) Japee brother's medical publisher(p) LTD, p.140-142.

Billings, D.M. \& Halastead, J.A. (2005): Teaching in Nursing: A Guide for Faculty, (2 ${ }^{\text {nd }}$ Pdf edition. London: W.B.S. Saunders Company, pp 1-16, pp 54-60.

Brink, Y. \& Louw, Q. (2012). Clinical instruments: reliability and validity critical appraisal. Journal of Evaluation in Clinical Practice, 18(2), pp 1126-1132.

Bulechek, G.M., Butcher, H.K., Dochterman, J.M. \& Wagner, C.M. (2013). Nursing interventions classification (NIC). $6^{\text {th }}$ Edition. Jakarta: EGC.

Carlsson, E., Wann-Hansson, C. \& Pilhammar, E. (2009). Teaching during clinical practice: strategies and techniques used by preceptors in nursing education. Nurse Education Today, 29(5), pp 522-526.

Chan, Z.C.Y. (2019). Nursing students' view of critical thinking as 'Own thinking, searching for truth, and cultural influences'. Nurse Education Today, 78, pp 14 -18.

Clark, C.M. (2008). Student Voices on Faculty Incivility in Nursing Education: A Conceptual Model. Nursing Education Perspectives, 29(5), pp 284-289.

Collier, A.D. (2018). Characteristics of an effective nursing clinical instructor: The state of the science. Journal of 
Clinical Nursing, 27(1-2), pp 363-374.

Croxon, L. \& Maginnis, C. (2009). Evaluation of clinical teaching models for nursing practice. Nurse Education in Practice, 9(4), pp 236-243.

Dwyer, C.P., Hogan, M.J., Harney, O.M. \& Kavanagh, C. (2016). Facilitating a student-educator conceptual model of dispositions towards critical thinking through interactive management. Educational Technology Research and Development, 65(1), pp 47-73.

Elçigil, A. \& Sarı, H. (2008). Students' Opinions About and Expectations of Effective Nursing Clinical Mentors. Journal of Nursing Education, 47(3), pp 118-23.

Elisha, S. (2010). An educational curriculum used to improve the knowledge and perceptions of certified registered nurse. Anesthetist Clinical Educators, AANA Journal, 76(4), pp 287-292.

Factor, E.M.R. \& de Guzman, A.B. (2017). Explicating Filipino student nurses' preferences of clinical instructors' attributes: AConjoint Analysis. Nurse Education Today, 55, pp 122-127.

Flood, L.S. \& Robinia, K. (2014). Bridging the gap: strategies to integrate classroom and clinical learning. Nurse Education Practice, 14(4), pp 329-332.

Gaberson, K.B. \& Oermann, M.H. (2010). Clinical Teaching Strategies in Nursing. $2^{\text {nd }}$ edition. New York: Springer Publishing.

Hallin, K. \& Danielson, E. (2010). Preceptoring Nursing Students: Registered Nurses' Perceptions of Nursing Students' Preparation and Study Approaches in Clinical Education. Nurse Education Today, 30(4), pp 296-302.

Hayajneh, F. (2011). Role Model Clinical Instructor as Perceived by Jordanian Nursing Students. Journal of Research in Nursing, 16(1), pp 23-32.

Heidari, M.R. \& Norouzadeh, R. (2015). Nursing students' perspectives on clinical education Journal of Advances in Medical Education and Professionalism, 3(1), pp 39-43.

Henderson, A., Cooke, M., Creedy, D.K. \& Walker, R. (2012). Nursing Students' Perceptions of Learning in Practice Environments: A Review. Nurse Education Today, 32(3), pp 299-302.

Heydari, A., Yaghoubinia, F. \& Roudsari, R. (2013). Supportive relationship: Experiences of Iranian students and teachers concerning student-teacher relationship in clinical nursing education. Iranian Journal of Nursing and MidwiferyResearch, 18(6), pp 467-474.

Hou, X., Zhu, D. \& Zheng, M. (2010). Clinical nursing faculty competence inventory-development and psychometric testing. Journal of Advanced Nursing, 67(5), pp 1109-1117.

Huang, L., Wang, Z., Yao, Y., Shan, C., Wang, H., Zhu, M., Lu, Y., Sun, P. \& Zhao, X. (2015). Exploring the association between parental rearing styles and medical students' critical thinking disposition in China. BMC medical education, 15, pp 1-8.

Ismail, L.M-N., Aboushady, R.M-N. \& Eswi A. (2016). Clinical instructor's behaviour: nursing student's perception toward effective clinical instructor's characteristics. Journal of Nursing Education and Practice, 6(2), pp 96-105.

Jansson, I. \& Ene, K.W. (2016). Nursing students' evaluation of quality indicators during learning in clinical practice. Nurse Education in Practice, 20, pp 17-22.

Jasemi M., Whitehead B., Habibzadeh H., Esmaeili Z.R. \& Rezaie S.A. (2018): Challenges in the clinical education of the nursing profession in Iran: A qualitative study. Nurse Education Today, 67, pp 21-26

Jouybari, L. \& Sanagoo, A. (2009). An effective instructor: A deep look at students and instructors' experiences and perspectives. Strides in Development of Medical Education Journal, 6(2), pp 119-28 (Persian). 
Kamel, F.F. (2010) Study the Effectiveness of Teaching the Clinical Administrative Course by Using Computer Based Training in Developing Nurse Intern Administrative Knowledge and Skills at Banha University, Egypt, pp 87.

Kan, Z. \& Stabler-Haas, S. (2009). Fast Facts for The Clinical Nursing Instructor Clinical Teaching in A Nutshell, Springer Publishing Company, LLC. New York, pp 3- 14.

Khan, B.A., Ali, F., Vazir, N., Barolia, R. \& Rethan, S. (2012). Students' perceptions of clinical teaching and learning strategies: A Pakistani Perspective. Nurse Education Today, 32(1), pp 85-90.

Khan, N., Shafi, S. \& Akhtar, S. (2015). Availability of clinical nurse instructor enhance the application of theory into practice in tertiary care hospitals (LRH, KTH, HMC), KPK, Peshawar, Pakistan. International Journal of Innovative Research and Development, 4(1), pp 293-297.

Knox, J. E. \& Mogan, J. (1985). Important clinical teacher behaviours as perceived by university nursing faculty, students and graduates. Journal of Advanced Nursing, 10(1), pp 25-30.

Kube, M. (2010). The Relationship of Nursing Faculty Clinical Teaching Behaviors to Student Learning. Dissertation for Doctor in Education from College of Saint Mary College of Saint Mary, United States -- Nebraska.

Labrague, L.J., McEnroe-Petitte, D.N., D'Souza, M.S., Hammad, K.S. \& Hayudini, J.N.A. (2019). Nursing faculty teaching characteristics as perceived by nursing students: An integrative review. Scandanavian Journal of Caring Sciences, 34(1), pp 23-33.

LaFauci, F. (2009). Second Year Associate Degree Nursing Students and Nursing Faculty Attitudes towards Clinical Educational Experiences. Dissertation, Dowling College, United States, New York.

Lau, Y. \& Wang, W. (2013). Development and evaluation of a learner-centered training course on communication skills for baccalaureate nursing students. Nurse Education Today, 33(12), pp 1617-1623.

Lejonqvist, G.B., Eriksson, K. \& Meretoja, R. (2016). Evaluating clinical competence during nursing education: A comprehensive integrative literature review. International Journal of Nursing Practice, Volume 22, Issue 2 April 2016 Pages 142-151.

Lovic, R., Prlic, N., Barac, I., Pluzaric, J., Puseljic, S., Berecki, I. \& Radic, R. (2014). Specificities and differences in nursing students' perceptions of nursing clinical faculties' competences. Journal of Professional Nursing, 30(5), pp 406-417.

Madhavanprabhakaran, G.K., Shukri, R.K., Hayudini, J. \& Narayanan, S.K. (2013). Undergraduate Nursing Students' Perception of Effective Clinical Instructor: Oman. International Journal of Nursing Science, 3(2), pp 38-44.

Mahfouz, H.E. (2011). Developing Clinical Teaching Skills of the Assisting Teaching Staff at Benha Faculty of Nursing. Doctorate Thesis, Faculty of Nursing, Benha University, Egypt.

Mlek, M. (2011). Nursing Learning Experiences in Clinical Setting. Unpublished Master Thesis, Concordia University, Montreal, Quebec, Canada, pp 25-30.

Molodysky, E., Sekelja, N. \& Lee, C. (2006). Identifying and training effective clinical teachers--new directions in clinical teacher training. Australian Family Physician, 35(1-2), pp 53-55.

Mousa, F., Adam, S. \& Hassan, R. (2012). Developing and Validating Standards for Effective Clinical Training Settings for Nurse Students. Master Thesis, Faculty of Nursing, Ain Shams University, Egypt.

Nazari, R. \& Mohammadi, E. (2015). Characteristics of competent clinical instructors: a review of the experiences of nursing students and instructor. Journal of Nursing and Midwifery Sciences, 2(2), pp 11-22.

Nelson, N. (2011). Beginning Nursing Students Perceptions of The Effective Characteristics and Caring Behaviors of Their Clinical Instructor. Dissertation. Capella University, USA. 
Oermann, M.H. \& Gaberson, K.B. (2013). Evaluation and Testing in Nursing Education. $3^{\text {rd }}$ edition. New York: Springer Publishing.

Parvan, K., Hosseini, F.A. \& Bagherian, S. (2018). The Relationship Between Nursing Instructors' Clinical Teaching Behaviors and Nursing Students' Learning in Tabriz University of Medical Sciences in 2016. Education for Health, 31(1), pp 32-38.

Polit, D. \& Tatano-Beck, C. (2008). Nursing research: Generating and assessing evidence for nursing practice. $8^{\text {th }}$ edition. Philadelphia PA: Lippincott Williams \& Wilkins.

Rowbotham, M. \& Owen, R.M. (2015). The effect of clinical nursing instructors on student self-efficacy. Nurse Education in Practice, 15(6), pp 561-566.

Sadeghi A., Oshvandi K. \& Moradi Y., (2019). Design of Clinical Competency Model for nursing undergraduates, Explaining the inhibitory characteristics of clinical instructors in the process of developing clinical competence of nursing students: a qualitative study. Journal of Family Medicine and Primary Care, 8(5), pp 1664-1670.

Salimi, T., Khodayarian, M., Rajabioun, H., Alimandegari, Z., Anticchi, M., Javadi, S. \& Namjoo, Z. (2012). A survey on viewpoints of nursing and midwifery students and their clinical instructors at Faculty of Nursing and Midwifery of Shahid Sadoughi University of Medical Sciences towards clinical education during 2009-2011. The Journal of Medical Education and Development, 7(3), pp 67-78.

Soliman, M.E., EL Sawi, K.A., Mohamed, L.A., Hashem, H.Y. \& El-Sebaee, H.A. (2006). Promoting Clinical Teaching Skill among Nursing Instructor at Faculties of Nursing, Faculty of Nursing, Cairo University, Egypt. The Third annual International Scientific Conference of Maternal Health Nursing Department, pp 56-67.

Sudh, R, (2013). Nursing education: Principles and concepts; nursing educational programs, Jaypee Brother's Medical Publishers Ltd, India. pp 208-213.

Van Graan, A.C., Williams, M.J. \& Koen, M.P. (2016). Clinical judgement within the South African clinical nursing environment: A concept analysis. Health SA Gesondheid, 21(2), pp 33-45.

Vanguri, P.R. \& Konin, J. (2008). The Acquisition of Instructional Strategies through Four Sessions' Athletic Trainer Clinical Instructor Workshop. The Internet Journal of Allied Health Sciences and Practice, 6(1), pp 1-10.

World Health Organization (2005). Effective teaching: A Guide for Educating Health Care Providers. Reference Manual, Geneva; pp 90-91. 